Rochester Institute of Technology

RIT Scholar Works

Theses

$12-2017$

\title{
Optimization of Residential Battery Energy Storage System Scheduling for Cost and Emissions Reductions
}

Zachary Olivieri

zo3803@rit.edu

Follow this and additional works at: https://scholarworks.rit.edu/theses

\section{Recommended Citation}

Olivieri, Zachary, "Optimization of Residential Battery Energy Storage System Scheduling for Cost and Emissions Reductions" (2017). Thesis. Rochester Institute of Technology. Accessed from 


\begin{abstract}
$\mathrm{R} \cdot \mathrm{I} \cdot \mathrm{T}$
Optimization of Residential Battery Energy Storage System Scheduling for Cost and Emissions Reductions

by

Zachary Olivieri
\end{abstract}

\begin{abstract}
A Thesis Submitted in Partial Fulfillment
of the Requirements for the Degree of

Masters of Science in Sustainable Engineering
\end{abstract}

Department of Industrial and Systems Engineering

Kate Gleason College of Engineering

Rochester Institute of Technology

Rochester, NY

December, 2017 


\section{DEPARTMENT OF INDUSTRIAL AND SYSTEMS ENGINEERING \\ KATE GLEASON COLLEGE OF ENGINEERING \\ ROCHESTER INSTITUTE OF TECHNOLOGY \\ ROCHESTER, NY}

\section{M.S. DEGREE THESIS}

The M.S. Degree thesis of Zachary Olivieri has been examined and approved by the thesis committee as satisfactory for the thesis requirements for the Master of Science Degree

Approved by:

Dr. Katie McConky, Thesis Advisor

Date

Dr. Brian Thorn

Date

Dr. Eric Hittinger

Date 


\begin{abstract}
The introduction of dynamic electricity pricing structures such as Time of Use (TOU) rates and Day Ahead Pricing (DAP) in residential markets has created the possibility for customers to reduce their electric bills by using energy storage systems for load shifting and/or peak load shaving. While there are numerous system designs and model formulations for minimizing electric bills under these rate structures the use of these systems has the potential to cause an increase in emissions from the electricity system. The Increase in emissions is linked to the difference in fuel mix of marginal generators throughout the day as well as inefficiencies associated with energy storage systems. In this work a multiobjective optimization model is designed to optimize reduction in cost of electricity as well as reduction in carbon dioxide $\left(\mathrm{CO}_{2}\right)$ emissions from the electricity used by residential customers operating a battery energy storage system under dynamic pricing structures. A total of 22 different regions in the US are analyzed. Excluding emissions from the model resulted in an annual increase of $\mathrm{CO}_{2}$ emissions in all but one region ranging from $60-2000 \mathrm{~kg}$ per household. The multi-objective model could be used to economically reduce these additional emissions in most regions by anywhere from $5-1300 \mathrm{~kg}$ of $\mathrm{CO}_{2}$ per year depending on the region. When using the multi-objective model several regions had a net decrease in $\mathrm{CO}_{2}$ emissions compared to not using a battery system but most had a net increase.
\end{abstract}




\section{Table of Contents}

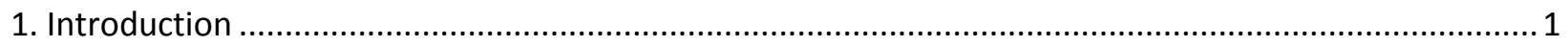

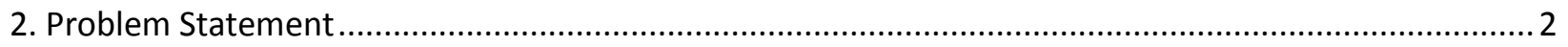

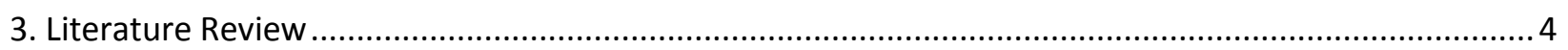

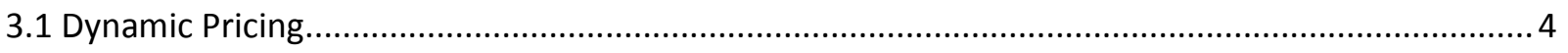

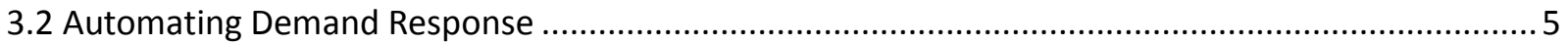

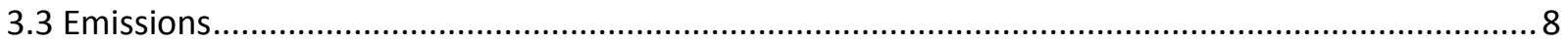

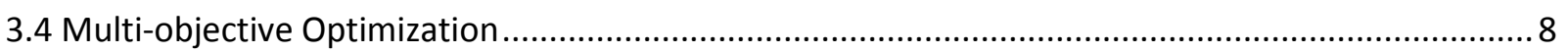

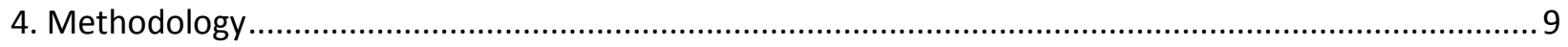

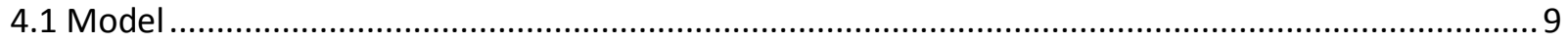

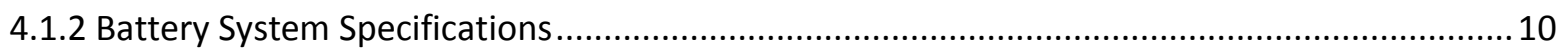

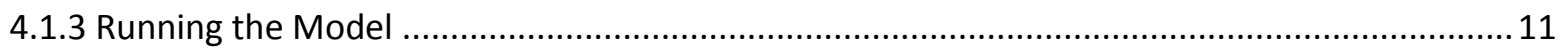

4.2 Multi-Objective Optimization Technique ................................................................................. 11

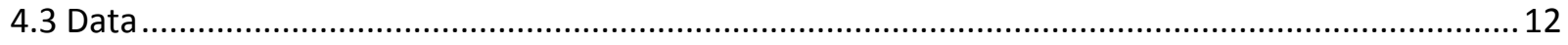

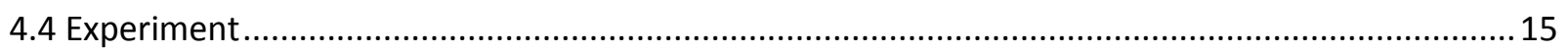

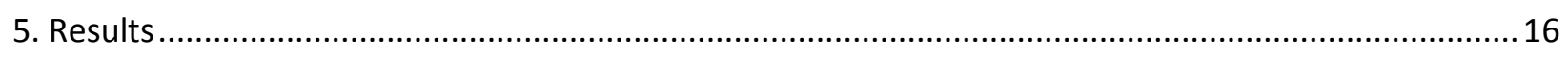

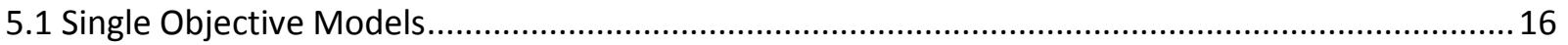

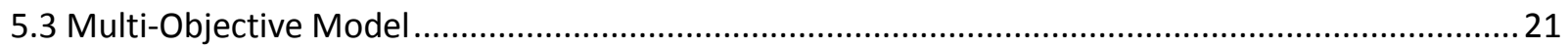

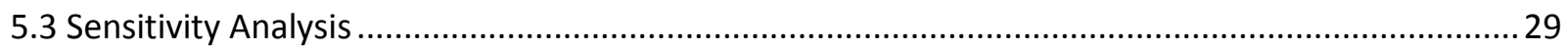

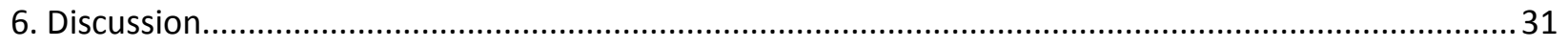

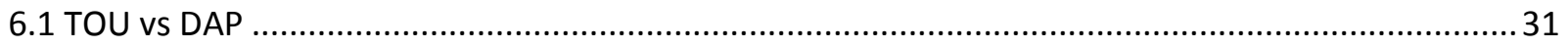

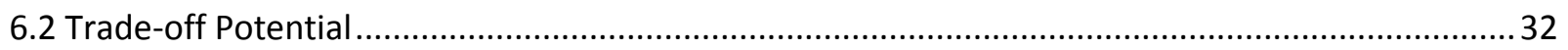

6.3 Relationship between Grid Resource Mix and Trade-off Potential ............................................. 46

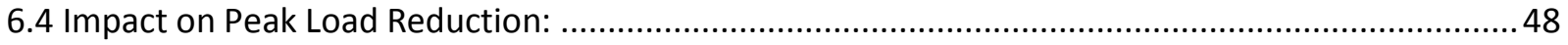

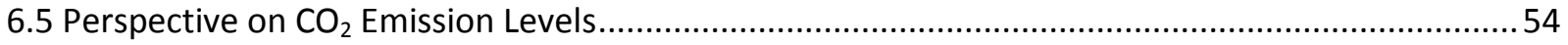

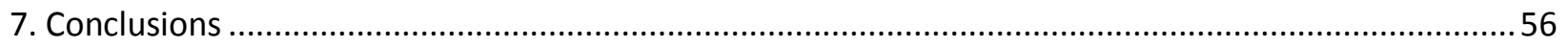

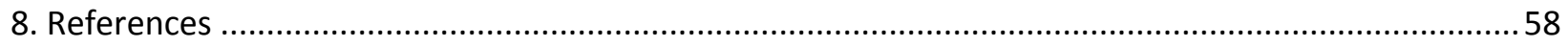




\section{List of Tables:}

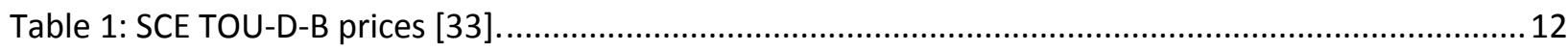

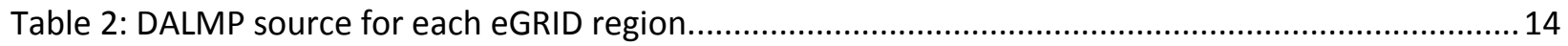

Table 3: Percent reductions of cost and $\mathrm{CO}_{2}$ emissions for the single objective models.........................17

Table 4: Range of cost and $\mathrm{CO}_{2}$ emissions between the cost-only and the emissions-only models..........20

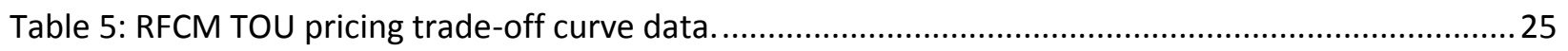

Table 6: RFCM DAP trade-off curve data. ............................................................................................ 26

Table 7: Cost of reducing $\mathrm{CO}_{2}$ emissions using the multi-objective model compared to the cost-only model.

Table 8: Comparison of cost and emissions reductions under DAP provided by the cost only-model and

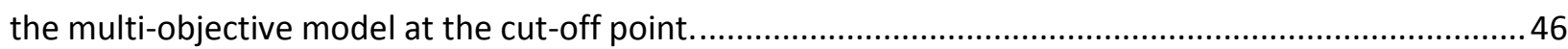

Table 9: Coal and natural gas generation percentages by region. ...................................................... 48

Table 10: Annual $\mathrm{CO}_{2}$ emissions from cost-only and multi-objective models. .........................................55 


\section{List of Figures:}

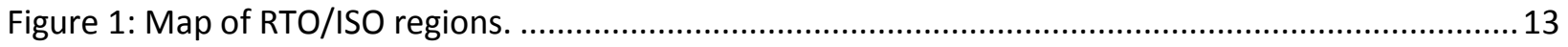

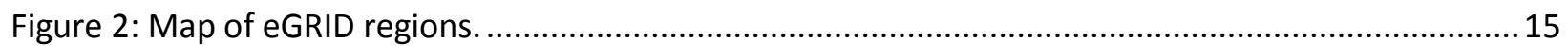

Figure 3: eGRID regions colored based on increase in $\mathrm{CO}_{2}$ emissions from the day-ahead cost model.... 18

Figure 4: eGRID regions selected for use with the multi-objective model.............................................2 21

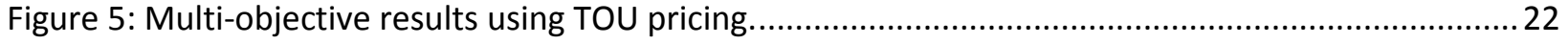

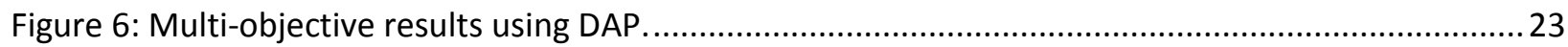

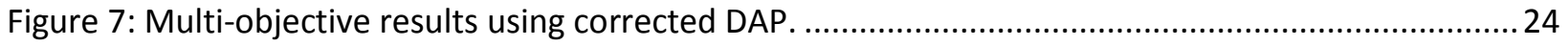

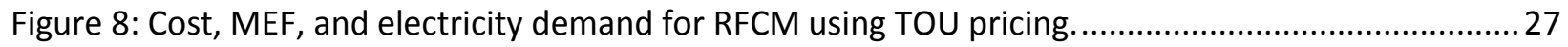

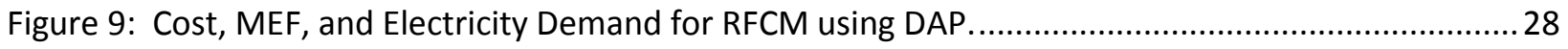

Figure 10: Sensitivity analysis of battery efficiency for the RFCM region. ..............................................29

Figure 11: Sensitivity analysis of battery capacity for the RFCM region.................................................. 30

Figure 12: Sensitivity analysis of battery charge rate for the RFCM region. ............................................ 31

Figure 13: $\mathrm{CO}_{2}$ emissions from the cost-only model compared to the multi-objective model cut-off point

schedule using DAP.

Figure 14: eGRID regions colored by $\mathrm{CO}_{2}$ reductions achievable with the multi-objective model cut-off point under DAP 45

Figure 15: SPNO cost, MEF, and demand profiles from Wednesday through Friday..............................50

Figure 16: SRMV cost, MEF, and demand profiles from Wednesday through Friday. .............................51

Figure 17: RMPA cost, MEF, and demand profiles from Wednesday through Friday................................52

Figure 18: SPSO cost, MEF, and demand profiles from Wednesday through Friday.................................53

Figure 19: RFCM cost, MEF, and demand profiles from Wednesday through Friday. ..............................54 


\section{Introduction}

Access to electricity is essential to providing the standard of living upheld by the average American. It has long been a goal to ensure that people have access to uninterrupted and affordable electricity. However, as demand for electricity in this country continues to grow the costs of electric power generation, transmission, and distribution are increasing and the power markets are becoming stressed which may lead to a significant increase in the retail price of electricity over the coming years [1][2].

Of particular concern is the peak demand; enough capacity must be installed to meet the peak demand, but demand is only at this level for a small percentage of the time. As a result, the cost of meeting an increase in peak demand is high compared to the cost of meeting an increase in average off-peak demand [3]. One strategy being considered as a way to reduce peak demand is the implementation of dynamic electricity prices which charge more for electricity at times of higher demand rather than charging a fixed rate per kilowatt hour like the widely used fixed-rate pricing models. The goal of dynamic pricing is to modify the customers' behavior through financially incentivizing them to shift their high electrical demand activities to off peak hours. However, due to concerns that customers will not know how or not be willing to adjust their usage schedule to a dynamic pricing model there has been a variety of research into developing autonomous energy storage systems that customers could install to store energy during low price periods and supply energy during high price periods thus reducing the customer's electricity bill without them having to change their behavior. These systems can also be integrated with renewable energy technologies such as wind turbines and solar panels whose energy production is independent of changes in demand. In addition to saving money for the customer, if enough of these systems are used it can reduce peak demand thus saving money for the utilities and preventing the need for an increase in the retail price of electricity.

Using energy storage for load shifting may be an effective method for saving money with dynamic pricing. Energy storage also works well with intermittent renewable energy technologies whose production is not matched with demand. However, there is research that has shown that bulk energy storage can increase the emissions from energy production [4]. This is due to two main reasons; first is that energy storage has inherent inefficiencies and therefore requires more production to yield the same amount of energy. Second, is that marginal generators are in some cases cleaner than off-peak 
generators so the storage systems are potentially being charged using electricity from plants with higher emissions than ones that are operating when the storage system is supplying energy.

In the Paris Agreement nations across the globe committed to peaking and then reducing their greenhouse gas (GHG) emissions in order to have global emissions at net-zero in the second half of this century [5]. While commitment of the US federal government to this agreement is susceptible to change, many States are committed to reducing GHG's and have formed initiatives such as the Regional Greenhouse Gas Initiative (RGGI) and the Western Climate Initiative (WCI) that have established market based programs for reducing GHG's in the US. The power sector is an important target due to its large contribution to GHG emissions, generating 37\% of total US energy related CO2 emissions in 2015 [1]. As GHG reduction gains more attention on a national and global scale, increases in emissions from electricity production are a concern. With increased carbon regulations in the future being likely, generator operators will be looking for efficient ways to reduce emissions. On the other hand the implementation of dynamic pricing is likely to increase in an effort to reduce peak demand. There are potential benefits to be gained by designing an electricity storage system with the objective of reducing electricity bills under dynamic pricing rates while also minimizing emissions.

In this work a model is formulated to optimize the operation of a BESS under dynamic prices. The model uses multi-objective optimization techniques to find trade-offs between two objectives; minimizing the customer's electric bill and minimizing $\mathrm{CO}_{2}$ emissions resulting from operation of the system. This model helps provide a better understanding of the relationship between cost reduction and increased $\mathrm{CO}_{2}$ emissions for residential Battery Energy Storage Systems (BESSs) which may help utility companies and policy makers make more informed decisions in their efforts to promote the spread of peak load flattening strategies.

\section{Problem Statement}

Flattening peak electricity demand has been identified as a good method for reducing costs for the utilities and therefore reducing the price of electricity $[2,6]$. This is due to a number of factors including that peak demand dictates the amount of capacity and transmission that needs to be installed, that the marginal cost of electricity increases with demand, and that peaking plants often have higher operating 
costs [3]. Transmission losses are also highest during peak demand [6]. Rate structures with dynamic prices that reflect changes in demand such as real time pricing (RTP), day ahead pricing (DAP), and time of use (TOU) pricing models have been proposed as a method to help flatten peak demand through consumer response to changing prices and therefore lowering the cost of electricity production. BESSs have been suggested as a means of helping consumers capitalize on the benefits of dynamic pricing models without being required to alter their daily routines.

While the combination of dynamic pricing and consumers using BESSs may offer benefits to both the utilities and the consumers by providing a reduction in peak demand they also have the potential to increase emissions from power production which represents an increased cost to the utilities and consumers. Research has shown that bulk energy storage in the United States can contribute to a significant increase in emissions from the power sector due to efficiency losses inherent to energy storage as well as the displacement of energy generation from low emission generation facilities to facilities with higher emissions [4]. Carbon markets already exist in the US within States belonging to the RGGI and the $\mathrm{WCl}$ and there have been attempts such as the Clean Power Plan (CPP) to create nationwide GHG reduction targets for power plants. While efforts such as the CPP may be slowed or compromised due to changes in authorities, stricter $\mathrm{CO}_{2}$ regulations are likely to be imposed in the future. Increased regulation of $\mathrm{CO}_{2}$ will be an additional cost to utility companies which will likely increase the price of electricity to the consumer. Current mathematical models used for scheduling BESSs do not account for the increased emissions resulting from the system's operation. As increased emissions are likely to be a factor in the cost of electricity, models aimed at reducing cost should include effects on emissions.

Current research has yet to answer some important questions regarding BESS scheduling and the increased emissions that may result from them. These questions include: Do BESS schedules change if emissions are considered? If so, how will different generation profiles impact this change? What are the consequences of excluding emissions from scheduling models? What is the best schedule for providing cost reductions while also mitigating increases in emissions? In this work a mathematical model will be formulated with the purpose of scheduling the operation of a residential BESS with dynamic pricing to find a favorable trade-off between minimizing cost to the customer and minimizing marginal $\mathrm{CO}_{2}$ emissions from the system. A posteriori methods are used to generate a Pareto front which is analyzed to gain a better understanding of the relationship between reducing cost and reducing emissions. The model is run with a variety of parameters representing the grid resource mix and dispatch schedules of 
several regions within the United States in order to determine the effects of these regional characteristics on the solutions provide by the model. Sensitivity analysis is conducted by varying the efficiency, capacity, and charge rate of the battery system and observing the changes in cost and emissions reductions. Additionally a $\mathrm{CO}_{2}$ price forecast is used to evaluate the economic feasibility of the different multi-objective schedules. This work provides an understanding of the potential consequences associated with emissions increases from conventional BESS schedules and introduces a new scheduling model that takes $\mathrm{CO}_{2}$ emissions into consideration in addition to the cost of electricity.

\section{Literature Review}

This section contains a summary of works from the literature which pertain to several different categories relating to this work. These categories include dynamic electricity pricing, methods of automating demand response, evidence of the impact of demand response and energy storage on $\mathrm{CO}_{2}$ emissions, and multi-objective optimization techniques.

\subsection{Dynamic Pricing}

Peak electricity demand has long been the subject of research due to its influence on capacity decisions in power systems planning and management. Traditionally utility planners would make forecasts of expected peak demand which had to meet a somewhat arbitrary loss of load probability and they would plan capacity additions based on these forecasts [7]. However these forecasting methods started to become less reliable around the 1970s due to a number of changes to the status-quo such as sharp increases in fuel prices and declining heat rate efficiency improvements in generation technologies [8]. These changes caused increased financial stresses to the utilities which led to research which focused on ways to alleviate these stresses. In a work on electric power generating system economics Telson [8] suggests that utilities will benefit from determining more optimal reliability targets for capacity forecasting and from devising pricing schemes that reduce peak loads. The theory behind this latter suggestion was presented in a work by Boiteux [9] called "Peak-Load Pricing" in which Boiteux claims that pricing mechanisms have a strong potential for increasing productivity of the power sector. The proposed need of the utilities to flatten peak demand gave rise to the idea of demand side management (DSM) which Gellings describes as "the planning and implementation of those electric utility activities 
designed to influence customer uses of electricity in ways that will produce desired changes in the utility's load shape" [7]. Gellings proposed that alternative pricing structures and other methods which leave consumption choices up to the customer are among the most effective methods of meeting demand side goals. Alternative pricing structures aimed at flattening peak demand have become a widely researched subject and are commonly referred to as dynamic pricing which includes time of use (TOU) rate structures, real time pricing (RTP), and several other rate structures.

In an effort to determine if TOU rate structures could produce significant enough changes in load distributions to warrant their implementation the Department of Energy (DOE) conducted a number of TOU rate experiments beginning in 1975 [10]. Aigner evaluated the DOE experiments and found weaknesses in designs of many of the experiments which left him unable to make any definitive conclusions on the costs and benefits of TOU pricing [10]. Many more TOU rate experiments have been conducted since Aigner's assessment in an effort to quantify their impacts on energy usage. The state of California has been one of the more active states in performing such experiments in part due to an energy crisis experience by the state in 2000 and 2001. A statewide pricing pilot (SPP) conducted in California was evaluated by Charles River Associates (CRA) [11] who found that a significant amount of demand response can be achieved through TOU and dynamic pricing and that the impacts are significantly larger if the customer is using an "enabling technology" such as a smart thermostat. Farqui et. al. [2] used findings from a number of TOU studies including the CRA study to estimate the value of peak demand reduction facilitated by TOU pricing on a national scale. They claim that a reduction in peak demand as low as five percent could result in savings of $\$ 35$ billion over a twenty year period.

\subsection{Automating Demand Response}

A significant portion of current research involving dynamic pricing centers around the development of methods which can help customers increase their response to rate changes in order to provide higher reductions in peak load. Some of these methods include the regulation of appliances and the use of electrical storage systems.

Appliance regulation under a dynamic pricing structure works by first categorizing different appliances based on the deferability and interruptibility of their loads and then determining an optimal schedule for running the appliances so that cost is minimized and the appliances are still able to complete their desired function. Autonomous regulation of appliances can be achieved with the use of a smart meter and scheduler which is capable of turning appliances on and off as well as controlling their operating 
mode. Common characteristics of mathematical models used for the development of optimal appliance load schedules are summarized in [12].

There have been a variety of topics explored by appliance load scheduling research conducted within the past several years, the following are few examples. The authors of [13] developed a load control model for use under a real time pricing (RTP) scheme which incorporated a method for predicting future electricity prices based on prices of the day before and of the same day last week. In [14] an integer linear programing based optimization was used to develop a load schedule which minimizes peak hourly demand rather than using the more common objective of minimizing electricity cost. Two optimization techniques, stochastic and robust optimization, are compared in [15] with regards to their effectiveness at determining an appliance load schedule which minimizes cost under RTP; both methods were determined to be effective with the stochastic method having a higher computational burden but providing better cost reductions. In [16] a load scheduling model is developed which uses thermal constraints in addition to electrical constraints, the model also can account for the introduction of energy storage and plug in hybrid electric vehicles (PHEVs) into the system. A model is used to optimize load schedules in [17] which incorporates energy storage and photovoltaics (PVs) into the system, the model is designed for use under TOU rates. In [18] an appliance load schedule is developed for a household using energy storage and a PHEV that minimizes cost and results in a reduction in the peak to average ratio (PAR) index of the load profile.

Similarly to appliance scheduling, energy storage system management uses smart meters and schedulers to autonomously help customers benefit from dynamic pricing. Rather than making decisions for each appliance in the house, energy storage system management generally works by determining when the battery system is charging, when the house draws electricity from the grid, and when it draws electricity from the storage system [6]. Some of the more current research relating to energy storage system management involves topics such as optimal sizing of the system, methods of residential electricity demand prediction for use with the scheduling model, performance of the scheduling model under different pricing schemes, and scheduling for systems with additional features such as photovoltaics, fuel cells, and multiple battery types.

The authors of [6] designed a residential battery energy storage system that uses a model to determine the optimal schedule for electricity bill minimization at the beginning of each day, the model sets constraints for the depth of discharge (DOD) and maximum charging rate of the battery in order to reduce impacts on the life of the battery. Also in [6] statistical machine learning techniques are used to 
predict the households' energy demand for input into the scheduling model. In [25] an energy storage management model is designed for use under TOU rates, the schedule is uniform in order to mitigate wear on the battery and future demand predictions needed for the model are made using data on residents' activity of daily life (ADL).

In [19] the performances of several different algorithms commonly used for battery system scheduling are compared with respect to their dependency on battery characteristics such as capacity and charge/discharge rate. They found that an action dependent heuristic dynamic programing (ADHDP) model performed the best over the widest range of battery specifications.

In [20] two different TOU rate structures are compared regarding their effects on optimal sizing and scheduling of a battery system coupled with photovoltaics (PVs), the cost function of the scheduling model included the cost of purchasing electricity as well as costs from degradation of the batteries. They found that TOU pricing with a higher margin between off-peak and on-peak prices improved economic efficiency of the battery energy storage system.

In [21] optimal scheduling of a hybrid electric energy storage system is determined, the system uses two types of batteries, one as the primary storage component (lead acid) and another as a buffer (lithium ion) to improve the lifespan of the primary batteries. A second model is used in [21] to optimize system specifications based on budgetary and volumetric constraints. Scheduling for a system including battery energy storage and a fuel cell with combined heat and power (CHP) is optimized in [22], the model uses predictions of both thermal and electric power demand and is solved using an imperialistic competition algorithm.

In [23] day ahead scheduling is determined for a battery storage system with PVs using reinforce learning technique that does not require predictions of future PV generation or electricity demand but instead relies on precise estimates of remaining energy in the storage module. In [24] the economic benefits of operating a residential battery storage system connected to PVs under TOU rates with net metering are investigated, a simple model is used for operation of the storage system in charges during the lowest price period and discharges during the highest price period. Optimal size and scheduling is determined in [26] for a PV and battery storage system operating under dynamic pricing which uses second life batteries from electric vehicles. 


\subsection{Emissions}

Energy storage helps electricity customers to shift portions of their peak demand to off-peak periods. Dynamic pricing schemes have been designed to incentivize customers to reduce their peak demand. Customers can use energy storage systems to increase the benefits they can gain from dynamic pricing and by doing so also reduce their demand at peak periods which is favorable to the utilities. However some research has shown that battery energy storage and dynamic pricing can in many regions result in an increase in $\mathrm{CO}_{2}$ emissions which is an important factor not considered in current battery system scheduling models. In [27] lifecycle greenhouse gas emissions of large scale energy storage systems are compared and it is found that a large portion of the lifecycle emissions result from the generation of the stored electricity and that when coupled with fossil fuel generation, inefficiencies in battery storage systems are a significant source of greenhouse gas emissions. In [28] it is argued that dynamic pricing will reduce the within-day and across-day variance of electricity demand and the short-run impact of this reduced variance on $\mathrm{SO}_{2}, \mathrm{NO}_{x}$, and $\mathrm{CO}_{2}$ emissions is estimated in the different North American Electric Reliability Council (NERC) regions. The results varied by region and in many of the regions a reduction in both within-day and across-day variance of electricity load caused an increase in emissions. It was determined that the results were correlated with changes in fossil fuel generation; in regions where a decrease in load variance resulted in an increase in fossil fuel generation emissions tended to increase. Such regions used a high percentage of fossil fuel generation for baseload and in some of them hydro power was used during peak times. In [4] the effect on net emissions of $\mathrm{SO}_{2}, \mathrm{NO}_{\mathrm{x}}$, and $\mathrm{CO}_{2}$ from bulk energy storage used for energy arbitrage is estimated using marginal emissions factors (MEFs) developed in [29] as a metric for assessing avoided emissions from displaced energy. The results showed that performing arbitrage with energy storage caused a non-trivial increase in $\mathrm{CO}_{2}$ emissions. This work will look at including emissions in battery storage system scheduling models in order to minimize electricity cost as well as emissions.

\subsection{Multi-objective Optimization}

A scheduling model designed to minimize both electricity costs and emissions will need to use a multiobjective optimization technique to find a solution. In multi-objective optimization it is unlikely to find a solution that minimizes (or maximizes) every objective but for a constrained problem there will be a number of Pareto optimal points that form a Pareto front [30]. At each Pareto optimal point there is a trade-off between the multiple objectives and no objective can be improved without worsening at least 
one of the other objectives; often when performing multi-objective optimization the desired solution is a large set of Pareto optimal solutions or the entire Pareto front [30]. There are a number of methods used for solving multi-objective optimization problems; one of the most common is the weighted-sum approach which works by transforming the multi-objective problem into a series of single-objective problems in which weights are assigned to the different objectives to form the Pareto front [31]. Other methods include the equality constraint method, the normal constraint method, the normal boundary intersection (NBI) method, the adaptive weighted-sum method, and heuristic methods using simulated annealing and genetic algorithms. A brief summary of these methods is presented in [31] in addition to the development and analysis of the adaptive weight-sum method.

\section{Methodology}

This section presents the model as well as the data that the model uses. It also contains a description of the experiment.

\subsection{Model}

The model used was developed in [6] and was modified by adding an additional objective function and constraint to minimize marginal emissions. This model was chosen because it is concise and effective and can easily be altered to minimize marginal emissions. The model was used to schedule one week of operation of a battery energy storage system.

Sets:

$\mathrm{T}=\{1, \ldots, \mathrm{n}\}$

Time intervals

\section{Parameters:}

$p_{i}$

$c_{i}$

$f_{i}$

I

$e$

C
Electricity demand $(\mathrm{kW})$ at time interval $\mathrm{i}$

Electricity cost $(\$ / \mathrm{kWh})$ at time interval i

Marginal emission factor $(\mathrm{g} / \mathrm{kWh})$ at time interval $\mathrm{i}$

Length of time interval ( $h$ )

Inefficiency parameter (\%)

Battery capacity (kWh) 


\section{$\underline{\text { Decision variables }}$}

$\mathrm{S}_{\mathrm{i}}$

$\mathrm{d}_{\mathrm{i}}$

$m_{i}=\left(p_{i}+s_{i}-d_{i}\right) * I * c_{i}, \forall i \in T$

$o_{i}=\left(p_{i}+s_{i}-d_{i}\right) * I * f_{i}, \forall i \in T$

Objective functions:

$\min \sum_{i=1}^{n} m_{i}$

$\min \sum_{i=1}^{n} o_{i}$

Constraints:

(1) $\quad s_{i} \geq 0, \quad \forall i \in T$

(2) $\quad d_{i} \geq 0, \quad \forall i \in T$

(3) $s_{i} \leq C / 2.7, \quad \forall i \in T$

(4) $\quad \sum_{t=0}^{i} d_{t} \leq e \sum_{t=0}^{i} s_{t}, \quad \forall i \in T$

(5)

$$
\left(\sum_{t=0}^{i} s_{t}-\sum_{t=0}^{i} d_{t} / e\right) * I \leq C, \forall i \in T
$$

Power charged to battery $(\mathrm{kW})$ at time interval i

Power discharged from battery $(\mathrm{kW})$ at time interval i

Amount billed $(\mathscr{C})$ at ith interval

Marginal emissions (g) at ith interval

Minimize the amount billed

Minimize the marginal emissions produced
Non-negativity for charge/discharge of battery

Maximum charge rate restriction ( $C=$ rated capacity)

Battery cannot discharge more energy than what has been charged to the battery multiplied by the inefficiency parameter $e$ Energy stored in the battery cannot exceed its capacity

\subsubsection{Battery System Specifications}

The battery system specifications are based on those of the Tesla Powerwall which are:

- Useable capacity of $13.5 \mathrm{kWh}$

- $100 \%$ Depth of discharge

- $90 \%$ round trip efficiency

- Continuous power of $5 \mathrm{~kW}$ which equates to a C-rate of $\mathrm{C} / 2.7$ (charge and discharge rate are assumed to be the same for the purposes of this experiment). 


\subsubsection{Running the Model}

The model was written in the optimization modeling language Pyomo. In practice battery energy storage systems schedules are generally calculated one day at time since demand and cost predictions become less accurate as they try to predict further into the future. Since one week was modeled for this experiment the model code was modified so that scheduling for each day would not consider information regarding the following days. To do this, seven sub-sets of time intervals were created (one for each day of the week) and constraint 4 was split into seven constraints corresponding to each of the seven sub-sets. The initial battery charge was always set to zero. Microsoft Excel was used to organize all necessary data output from the model and was used for all calculations.

\subsection{Multi-Objective Optimization Technique}

The weighted sum method was used to solve the multi-objective optimization problem. The two objective functions needed to be normalized in order to form a single objective function using the weighted sum method. To do this the model was solved for each objective separately to provide one optimal value for cost and one for $\mathrm{CO}_{2}$ emissions, the cost and emissions objectives were normalized by dividing them by the corresponding optimal value. A single objective function was created by multiplying the normalized objectives by a weight and summing them together. The weights used were always a value between 0 and 1 and when added together they equaled 1 . The model was run multiple times while altering the weights and the results were used to form the Pareto front (trade-off curve). In this experiment the model was run with seven different sets of weights for each scenario investigated. Equation 6 is an example of the weighted sum objective function:

$$
\min \left(w_{m}\left(\sum_{i=1}^{n} m_{i}\right) / N_{m}\right)+\left(w_{o}\left(\sum_{i=1}^{n} o_{i}\right) / N_{o}\right)
$$

(6)

Where $m_{i}$ is the amount billed at interval $i, o_{i}$ is the CO2 emissions produced at interval $i, w_{m}$ and $w_{o}$ are the weights for the cost and emissions objectives respectively and $N_{m}$ and $N_{o}$ are the optimal values from the single objective optimization of cost and emissions which are used to normalize each objective. 


\subsection{Data}

Representative household energy demand:

The household energy consumption data is from the UMass Smart* Home Data Set [32], house B from the data set was used; a description of house B is below:

- House $B$ is located in western Massachusetts, is around 1700 square feet, has two floors, has four full time occupants, and uses central air. Data is available for 1 week in July of 2013 and provides per hour power consumption in kilowatts.

For simplicity the model assumes demand is known when making decisions, however, in practice the demand data used in battery scheduling models is generally a prediction and will therefore not be completely accurate.

\section{Electricity prices for different pricing schemes:}

Two different types of pricing schemes were tested with the model, a Time of Use (TOU) and a Day ahead Pricing (DAP) scheme. The TOU rate used was the Southern California Edison's TOU-D-B summer price [33]. This was used since it has a large difference between the on-peak and off-peak prices which increases the benefits of load shifting.

Table 1: SCE TOU-D-B prices [33].

\begin{tabular}{ccc}
\hline & Weekdays & \\
\hline Time of Day & Summer price $(\Phi / \mathrm{kWh})$ & Winter price $(\Phi / \mathrm{kWh})$ \\
\hline $8 \mathrm{am}-2 \mathrm{pm}$ & 17 & 16 \\
$2 \mathrm{pm}-8 \mathrm{pm}$ & 34 & 23 \\
$8 \mathrm{pm}-10 \mathrm{pm}$ & 17 & 16 \\
$10 \mathrm{pm}-8 \mathrm{am}$ & 13 & 14 \\
\hline Time of Day & Weekends & \\
\hline $8 \mathrm{am}-10 \mathrm{pm}$ & Summer price $(\$ / \mathrm{kWh})$ & 13 \\
$10 \mathrm{pm}-8 \mathrm{am}$ & 17 & 14 \\
\hline
\end{tabular}


The DAP used were the regional Day Ahead Local Marginal Prices (DALMPs) which are provided by the regional transmission operators (RTOs) and independent system operators (ISOs). A map [34] of the RTO and ISO regions is provided in Figure 1:

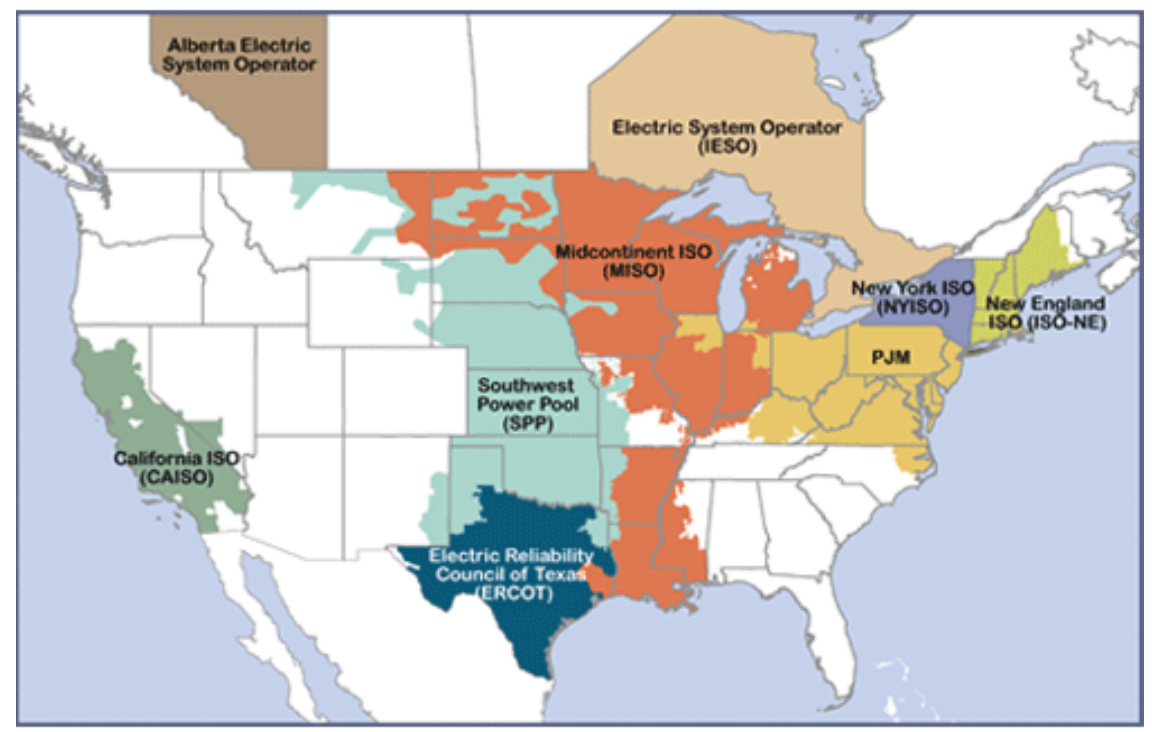

Figure 1: Map of RTO/ISO regions. [34]

As can be seen in the Figure 1 not all regions have an RTO/ISO, since a price is needed for each eGRID region (see Figure 2 below) the DALMP of the nearest region was used for regions without an RTO/ISO. Table 2 lists each eGRID region, the RTO/ISO they fall under, and the hub or node from which the DALMPs where obtained, the actual prices used can be found in the supplementary data. 
Table 2: DALMP source for each eGRID region.

\begin{tabular}{|c|c|c|}
\hline eGRID Region & RTO/ISO & Hub/Node \\
\hline NEWE & ISO-NE & .H.INTERNAL_HUB \\
\hline NYUP & NYISO & CNTRL \\
\hline NYLI & NYISO & LONGIL \\
\hline NYCW & NYISO & N.Y.C \\
\hline RFCE & PJM & NJ HUB \\
\hline RFCW & PJM & $\mathrm{OH} \mathrm{HUB}$ \\
\hline SRVC & PJM & Eastern HUB \\
\hline SRSO* & SPP & EES, SMEP \\
\hline FRCC* & SPP & EES, SMEP \\
\hline SRTV & PJM & Western HUB \\
\hline RFCM & MISO & Michigan HUB \\
\hline MORE & MISO & MINN HUB \\
\hline MROW & MISO & MINN HUB \\
\hline SRMW & MISO & Illinois HUB \\
\hline SRMV & SPP & EES, SMEP \\
\hline ERCT & ERCOT & HUBAVG \\
\hline SPSO & SPP & SPPSOUTH HUB \\
\hline SPNO & SPP & SPPNORTH HUB \\
\hline RMPA & SPP & LAM 345 \\
\hline NWPP* & CAISO & BLACK \\
\hline AZNM* & CAISO & BORDER6 \\
\hline CAMX & CAISO & WESTPT \\
\hline
\end{tabular}

${ }^{*}$ Regions do not have an RTO/ISO and are using prices from a nearby region 


\section{Marginal emission factors for different regions:}

MEFs developed in [29] were used for each of the EPA eGRID sub-regions, a map [35] of which is shown in Figure 2. The MEFs used are for the year 2014.

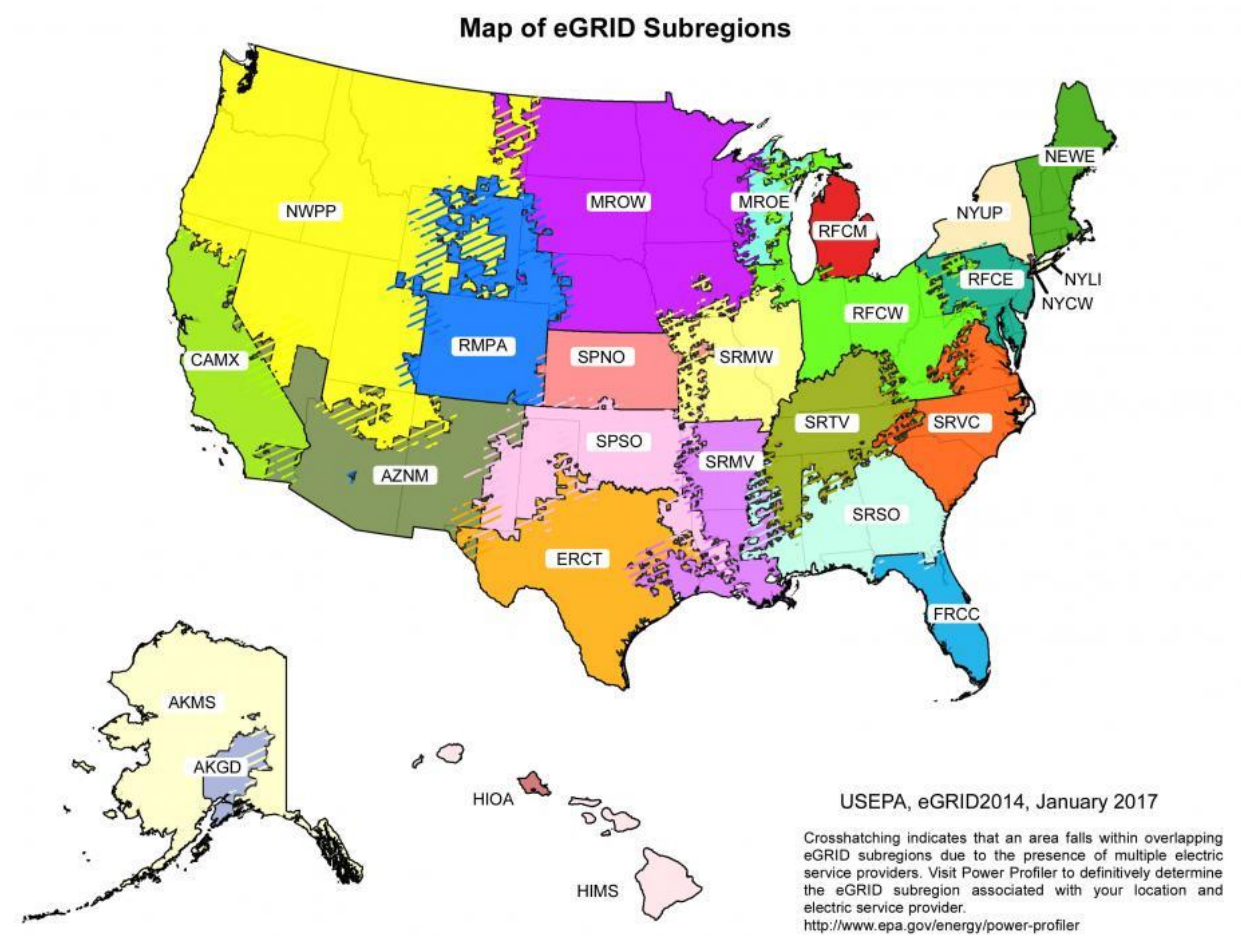

Figure 2: Map of eGRID regions. [35]

\subsection{Experiment}

The experiment had three general stages; running the single objective models for each region and observing the differences between the cost and emissions optimizations, running the multi-objective model for each region and generating trade-off curves, and conducting sensitivity analysis.

First three single objective models were run for each of the 22 regions, one for minimizing cost under TOU pricing, one for minimizing cost under DAP, and one for minimizing $\mathrm{CO}_{2}$ emissions. The models output the optimal values for either cost or $\mathrm{CO}_{2}$ emissions which were later used to normalize the separate objectives during the multi-objective optimization. The models also output a schedule of how much power was charged to and discharged from the battery each hour; the schedules' impacts on costs and emissions reduction was then calculated. 
For each region the multi-objective analysis was performed using TOU rates and then using DAP. For each scenario (region + pricing scheme) the multi-objective model was run seven times, each time the weights were altered. From each run of the model the battery schedule was recorded and the overall cost and $\mathrm{CO} 2$ emissions were calculated. The cost vs emissions was graphed for each scenario creating a Pareto curve with seven points from the multi-objective optimization and two points from the single objective optimizations. Once all of the Pareto curves were produced one region was selected for the sensitivity analysis.

The sensitivity analysis examined the impact of battery efficiency, battery capacity, and battery charge rate on the multi-objective optimization. Efficiencies of 60 to 100 percent were tested at 5 percent intervals; a Pareto curve was produced for each efficiency value resulting in 9 Pareto curves. Capacities of 5 to $50 \mathrm{kWh}$ were tested at $5 \mathrm{kWh}$ intervals thus producing 10 Pareto curves. Four different charge rates were tested; $C / 8, C / 4, C / 2$, and $1 C$ a Pareto curve was generated for each one.

\section{Results}

This section begins with the single objective model results, next presents the multi-objective model results, and ends with the sensitivity analysis.

\subsection{Single Objective Models}

For the single objective models for each region the percent reductions of cost and $\mathrm{CO}_{2}$ emissions are presented in Table 3. For each region three separate single objective models were run; two minimizing cost (one with TOU rates and one with DAP) and one minimizing emissions. The output of the model is a schedule of when and how much to charge and discharge the battery. Table 3 shows the resulting reduction in cost and $\mathrm{CO}_{2}$ emissions from using the battery system according to the optimal schedule. Negative values (in red) represent an increase rather than a reduction. Regions marked with an asterisk $(*)$ used altered day ahead prices because price data from the Southwest Power Pool (SPP) ISO contained abnormally high values for two hours during the weekend which had a significant impact on the optimization results. All regions that used data from SPP are in the table twice, the entries with an asterisk are using the same data for the weekdays but the data for the weekend are from one week earlier. The table is sorted by percentage increase in emissions using DAP from highest to lowest. Figure 3 shows the eGRID regions colored based on the increase in $\mathrm{CO}_{2}$ emissions from the day-ahead cost 
model compared to using no battery system. The color scale is from green to red, green regions have lower emissions and red regions have the highest emissions.

Table 3: Percent reductions of cost and $\mathrm{CO}_{2}$ emissions for the single objective models.

\begin{tabular}{|c|c|c|c|c|c|c|c|}
\hline \multirow{2}{*}{$\begin{array}{l}\text { Objective: } \\
\text { eGrid } \\
\text { Region }\end{array}$} & \multicolumn{2}{|c|}{ Cost (TOU) } & \multicolumn{2}{|c|}{ Cost (DAP) } & \multicolumn{3}{|c|}{ Emissions } \\
\hline & cost & em. & cost & em. & $\begin{array}{c}\text { Cost } \\
\text { (TOU) }\end{array}$ & $\begin{array}{c}\text { Cost } \\
\text { (DAP) }\end{array}$ & em. \\
\hline RFCM & $13.1 \%$ & $-19.6 \%$ & $23.4 \%$ & $-25.5 \%$ & $-25.7 \%$ & $-20.3 \%$ & $7.2 \%$ \\
\hline SPNO & $13.1 \%$ & $-8.6 \%$ & $37.2 \%$ & $-12.9 \%$ & $-24.1 \%$ & $-10.0 \%$ & $5.5 \%$ \\
\hline SPNO* & $13.1 \%$ & $-8.6 \%$ & $14.5 \%$ & $-12.8 \%$ & $-24.1 \%$ & $-28.3 \%$ & $5.5 \%$ \\
\hline ERCT & $13.1 \%$ & $-9.2 \%$ & $17.2 \%$ & $-12.6 \%$ & $-9.5 \%$ & $-11.6 \%$ & $1.5 \%$ \\
\hline SRMV* & $13.1 \%$ & $-11.3 \%$ & $9.1 \%$ & $-12.0 \%$ & $-4.4 \%$ & $-10.7 \%$ & $3.1 \%$ \\
\hline RMPA* & $13.1 \%$ & $-9.6 \%$ & $23.9 \%$ & $-11.7 \%$ & $-7.2 \%$ & $-31.7 \%$ & $4.9 \%$ \\
\hline SRMV & $13.1 \%$ & $-11.3 \%$ & $31.9 \%$ & $-11.6 \%$ & $-4.4 \%$ & $-1.8 \%$ & $3.1 \%$ \\
\hline RMPA & $13.1 \%$ & $-9.6 \%$ & $43.7 \%$ & $-9.9 \%$ & $-7.2 \%$ & $-5.2 \%$ & $4.9 \%$ \\
\hline SRTV & $13.1 \%$ & $-6.3 \%$ & $37.5 \%$ & $-8.9 \%$ & $-3.4 \%$ & $-6.5 \%$ & $2.0 \%$ \\
\hline SRMW & $13.1 \%$ & $-6.2 \%$ & $24.0 \%$ & $-8.4 \%$ & $-13.0 \%$ & $-8.2 \%$ & $3.3 \%$ \\
\hline MROW & $13.1 \%$ & $-7.6 \%$ & $26.8 \%$ & $-8.4 \%$ & $-7.7 \%$ & $-12.2 \%$ & $4.9 \%$ \\
\hline FRCC & $13.1 \%$ & $-8.9 \%$ & $31.9 \%$ & $-8.1 \%$ & $2.4 \%$ & $-5.5 \%$ & $3.9 \%$ \\
\hline SPSO* & $13.1 \%$ & $-10.0 \%$ & $9.1 \%$ & $-7.3 \%$ & $0.9 \%$ & $-8.4 \%$ & $4.3 \%$ \\
\hline SPSO & $13.1 \%$ & $-10.0 \%$ & $31.7 \%$ & $-7.3 \%$ & $0.9 \%$ & $25.6 \%$ & $4.3 \%$ \\
\hline FRCC* & $13.1 \%$ & $-8.9 \%$ & $9.1 \%$ & $-7.3 \%$ & $2.4 \%$ & $-5.5 \%$ & $3.9 \%$ \\
\hline RFCW & $13.1 \%$ & $-4.6 \%$ & $34.9 \%$ & $-6.7 \%$ & $-22.8 \%$ & $-40.5 \%$ & $2.7 \%$ \\
\hline NWPP & $13.1 \%$ & $-6.3 \%$ & $11.8 \%$ & $-6.5 \%$ & $-4.0 \%$ & $-2.9 \%$ & $3.0 \%$ \\
\hline MROE & $13.1 \%$ & $-6.7 \%$ & $26.8 \%$ & $-5.7 \%$ & $2.1 \%$ & $1.1 \%$ & $5.5 \%$ \\
\hline CAMX & $13.1 \%$ & $1.2 \%$ & $12.9 \%$ & $-5.3 \%$ & $10.0 \%$ & $-8.6 \%$ & $2.7 \%$ \\
\hline AZNM & $13.1 \%$ & $-7.3 \%$ & $18.6 \%$ & $-5.1 \%$ & $0.6 \%$ & $-2.5 \%$ & $3.3 \%$ \\
\hline SRVC & $13.1 \%$ & $-0.2 \%$ & $38.3 \%$ & $-3.3 \%$ & $-1.3 \%$ & $-3.4 \%$ & $5.5 \%$ \\
\hline NYCW & $13.1 \%$ & $2.3 \%$ & $28.4 \%$ & $-3.1 \%$ & $1.6 \%$ & $10.7 \%$ & $4.4 \%$ \\
\hline RFCE & $13.1 \%$ & $-3.2 \%$ & $37.3 \%$ & $-2.3 \%$ & $8.6 \%$ & $19.4 \%$ & $0.8 \%$ \\
\hline NEWE & $13.1 \%$ & $-2.1 \%$ & $29.9 \%$ & $-1.8 \%$ & $1.6 \%$ & $16.9 \%$ & $1.5 \%$ \\
\hline SRSO & $13.1 \%$ & $-4.3 \%$ & $31.9 \%$ & $-1.7 \%$ & $3.5 \%$ & $0.3 \%$ & $3.1 \%$ \\
\hline SRSO* & $13.1 \%$ & $-4.3 \%$ & $9.1 \%$ & $-1.0 \%$ & $35 \%$ & $1.3 \%$ & $3.1 \%$ \\
\hline NYLI & $13.1 \%$ & $-0.7 \%$ & $39.9 \%$ & $-0.8 \%$ & $10.1 \%$ & $23.6 \%$ & $1.7 \%$ \\
\hline NYUP & $13.1 \%$ & $1.2 \%$ & $26.4 \%$ & $2.1 \%$ & $8.3 \%$ & $21.1 \%$ & $4.1 \%$ \\
\hline
\end{tabular}




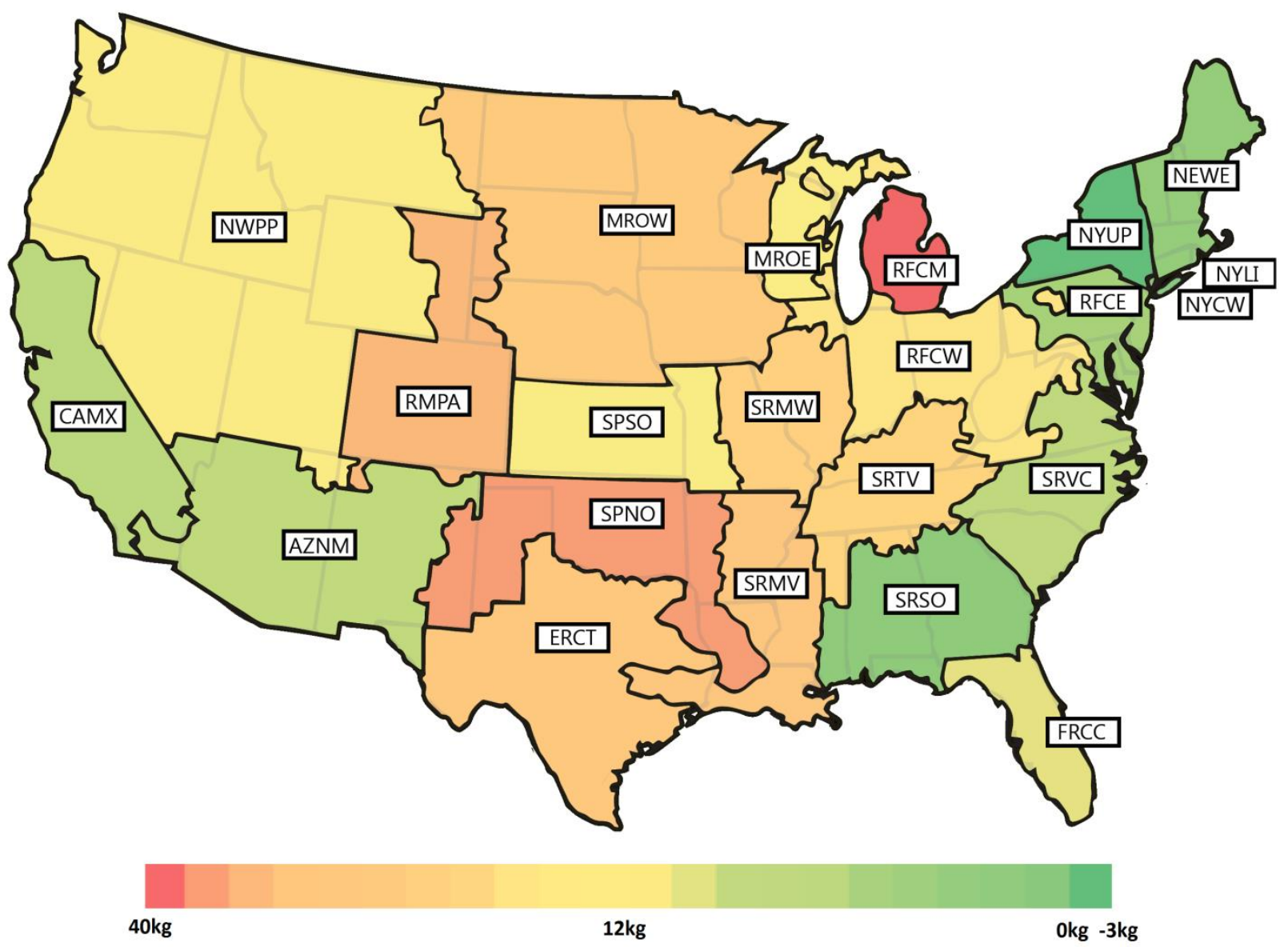

Figure 3: eGRID regions colored based on increase in $\mathrm{CO}_{2}$ emissions from the day-ahead cost model.

It can be seen from Table 3 that nearly all regions show an increase in emissions when optimizing for cost and a majority of the regions see an increase in cost when optimizing for emissions. The regions that show the highest percent increases in emissions when optimizing cost are good candidates for the multi-objective optimization because these are the regions in which the use of a battery energy storage system will have the greatest negative impact. Another method to determine the best candidates for the multi-objective optimization would be to determine regions in which the model has the most potential for balancing emissions reduction with cost reduction. One way to do this is to look at the range of cost and emissions reduction that can be achieved in each region by comparing the results from 
the cost minimization to those from the emissions minimization. These ranges can be used to calculate a ratio of cost to emissions reduction for each region using Equation 7:

$$
\frac{\left(\boldsymbol{m}_{E}-\boldsymbol{m}_{C}\right)}{\left(\boldsymbol{o}_{C}-\boldsymbol{o}_{E}\right)}=\boldsymbol{r}_{C: E}
$$

Where $m_{E}$ is the amount billed from the emissions optimization, $m_{C}$ is the amount billed from the cost optimization, $\mathrm{o}_{\mathrm{C}}$ is the emissions produced from the cost optimization, $\mathrm{o}_{\mathrm{E}}$ is the emissions produced from the emissions optimization, and $\mathrm{r}_{\mathrm{C}: \mathrm{E}}$ is a ratio of cost to $\mathrm{CO}_{2}$ emissions with units of $\$ / \mathrm{kg}$.

Regions with a lower ratio can reduce more emissions without sacrificing as much cost reduction. The ranges and ratios are shown in Table 4. The cost optimization provided a lower limit for electricity cost to the customer when using the battery energy storage system and an upper limit for $\mathrm{CO}_{2}$ emissions resulting from operation of the system. The emissions optimization provided an upper limit for cost and a lower limit for $\mathrm{CO}_{2}$ emissions. The differences between the upper and lower limits of cost and $\mathrm{CO}_{2}$ emissions are the ranges presented in Table 4. The ratios are determined by dividing the cost range by the $\mathrm{CO}_{2}$ range as shown in Equation 7. Regions are marked with an asterisk $(*)$ for the same reason as in Table 3. The table is sorted by the DAP ratios from lowest to highest. 
Table 4: Range of cost and $\mathrm{CO}_{2}$ emissions between the cost-only and the emissions-only models.

\begin{tabular}{|c|c|c|c|c|c|c|}
\hline \multirow{2}{*}{$\begin{array}{c}\text { eGrid } \\
\text { Region }\end{array}$} & \multicolumn{2}{|c|}{ TOU Ranges } & \multicolumn{2}{|c|}{ DAP Ranges } & \multicolumn{2}{|c|}{ Ratios (\$/kg) } \\
\hline & $\mathrm{CO} 2(\mathrm{~kg})$ & Cost (\$) & $\mathrm{CO} 2(\mathrm{~kg})$ & Cost (\$) & TOU & DAP \\
\hline SPSO & 23.87 & 5.64 & 19.38 & 0.79 & 0.24 & 0.04 \\
\hline SRMV* & 23.53 & 8.10 & 24.73 & 1.55 & 0.34 & 0.06 \\
\hline SPNO* & 30.63 & 17.22 & 39.87 & 2.73 & 0.56 & 0.07 \\
\hline SPSO* & 23.87 & 5.64 & 19.39 & 1.36 & 0.24 & 0.07 \\
\hline NWPP & 17.95 & 7.90 & 18.34 & 1.41 & 0.44 & 0.08 \\
\hline FRCC* & 16.93 & 4.97 & 14.86 & 1.15 & 0.29 & 0.08 \\
\hline RMPA* & 27.86 & 9.37 & 31.77 & 2.65 & 0.34 & 0.08 \\
\hline RFCM & 40.43 & 17.95 & 49.29 & 5.04 & 0.44 & 0.10 \\
\hline ERCT & 16.33 & 10.46 & 21.62 & 2.45 & 0.64 & 0.11 \\
\hline SPNO & 30.63 & 17.22 & 40.09 & 5.28 & 0.56 & 0.13 \\
\hline MROW & 28.06 & 9.64 & 29.83 & 4.05 & 0.34 & 0.14 \\
\hline SRMW & 20.05 & 12.05 & 24.79 & 3.47 & 0.60 & 0.14 \\
\hline RMPA & 27.86 & 9.37 & 28.32 & 4.32 & 0.34 & 0.15 \\
\hline SRMV & 23.53 & 8.10 & 24.11 & 4.40 & 0.34 & 0.18 \\
\hline MROE & 14.49 & 5.10 & 12.44 & 2.67 & 0.35 & 0.21 \\
\hline CAMX & 1.66 & 1.44 & 9.10 & 2.24 & 0.86 & 0.25 \\
\hline AZNM & 13.79 & 5.80 & 10.93 & 3.00 & 0.42 & 0.27 \\
\hline FRCC & 16.93 & 4.97 & 15.85 & 4.89 & 0.29 & 0.31 \\
\hline NYUP & 3.68 & 2.20 & 2.55 & 0.91 & 0.60 & 0.36 \\
\hline SRTV & 15.49 & 7.61 & 20.32 & 8.23 & 0.49 & 0.41 \\
\hline SRSO & 13.16 & 4.45 & 8.52 & 4.14 & 0.34 & 0.49 \\
\hline SRVC & 10.94 & 6.64 & 16.81 & 8.48 & 0.61 & 0.50 \\
\hline NYCW & 2.20 & 5.30 & 7.73 & 4.10 & 2.41 & 0.53 \\
\hline RFCW & 14.95 & 16.60 & 19.19 & 12.40 & 1.11 & 0.65 \\
\hline NEWE & 4.40 & 5.32 & 3.99 & 2.59 & 1.21 & 0.65 \\
\hline RFCE & 7.15 & 2.07 & 5.54 & 3.60 & 0.29 & 0.65 \\
\hline NYLI & 3.44 & 1.40 & 3.59 & 5.34 & 0.41 & 1.49 \\
\hline
\end{tabular}


It is important to note that the ratios presented in Table 4 do not represent the actual dollar value per $\mathrm{kg}$ of $\mathrm{CO} 2$ emissions reduced because the trade-off curves produced by the multi-objective optimization are not linear. However these ratios are useful in helping to predict which regions will have a more favorable trade-off between cost and emissions; these are the regions with lower ratios.

\subsection{Multi-Objective Model}

The 10 regions from Table 3 with the largest percentage increase in emissions under DAP and the 10 regions from Table 4 with the lowest ratio under DAP were predicted to gain the most benefits from using the multi-objective optimization scheduling model. Of the top 10 regions from each table, 8 are the same resulting in a total of 12 regions. The 12 regions are: FRCC, SRTV, RFCM, MROE, MROW, SRMW, SRMV, ERCT, SPSO, SPNO, RMPA, and NWPP. These regions are shown in green in Figure 4.

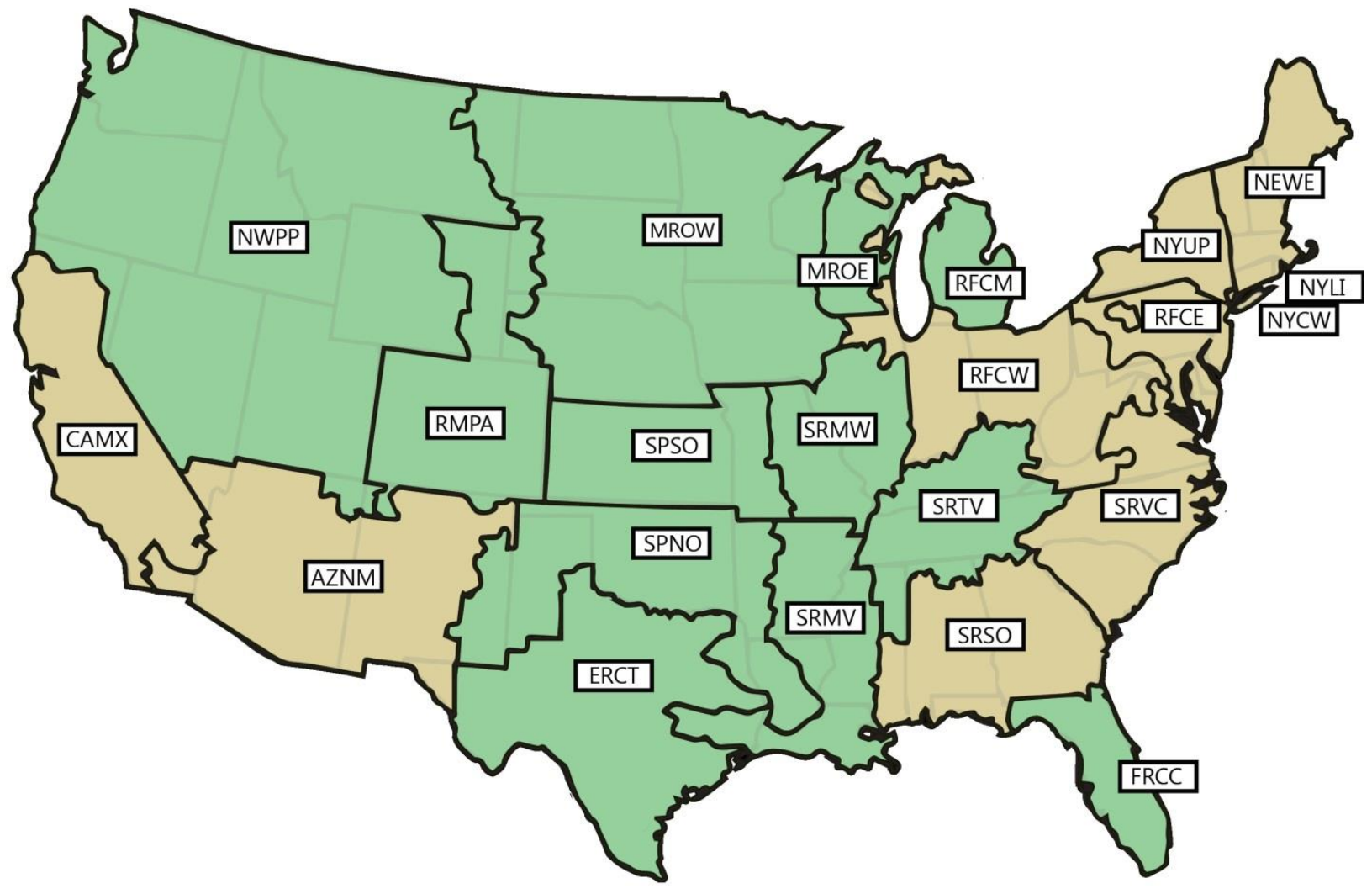

Figure 4: eGRID regions selected for use with the multi-objective model. 
The trade-off curves for all regions under DAP and TOU pricing are presented in Figures 5, 6, and 7. The 12 regions predicted to gain the most benefits from the multi-objective model have colored trade-off curves while the other regions have grey curves. The end points on the curves are from the single objective optimizations, the seven other points in the curves are from the multi-objective optimization. Curves that move greater distances from right to left on the $x$-axis (emissions) while simultaneously experiencing minimal increases on the $y$-axis (cost) are curves in which there are more favorable tradeoffs between costs and emissions.

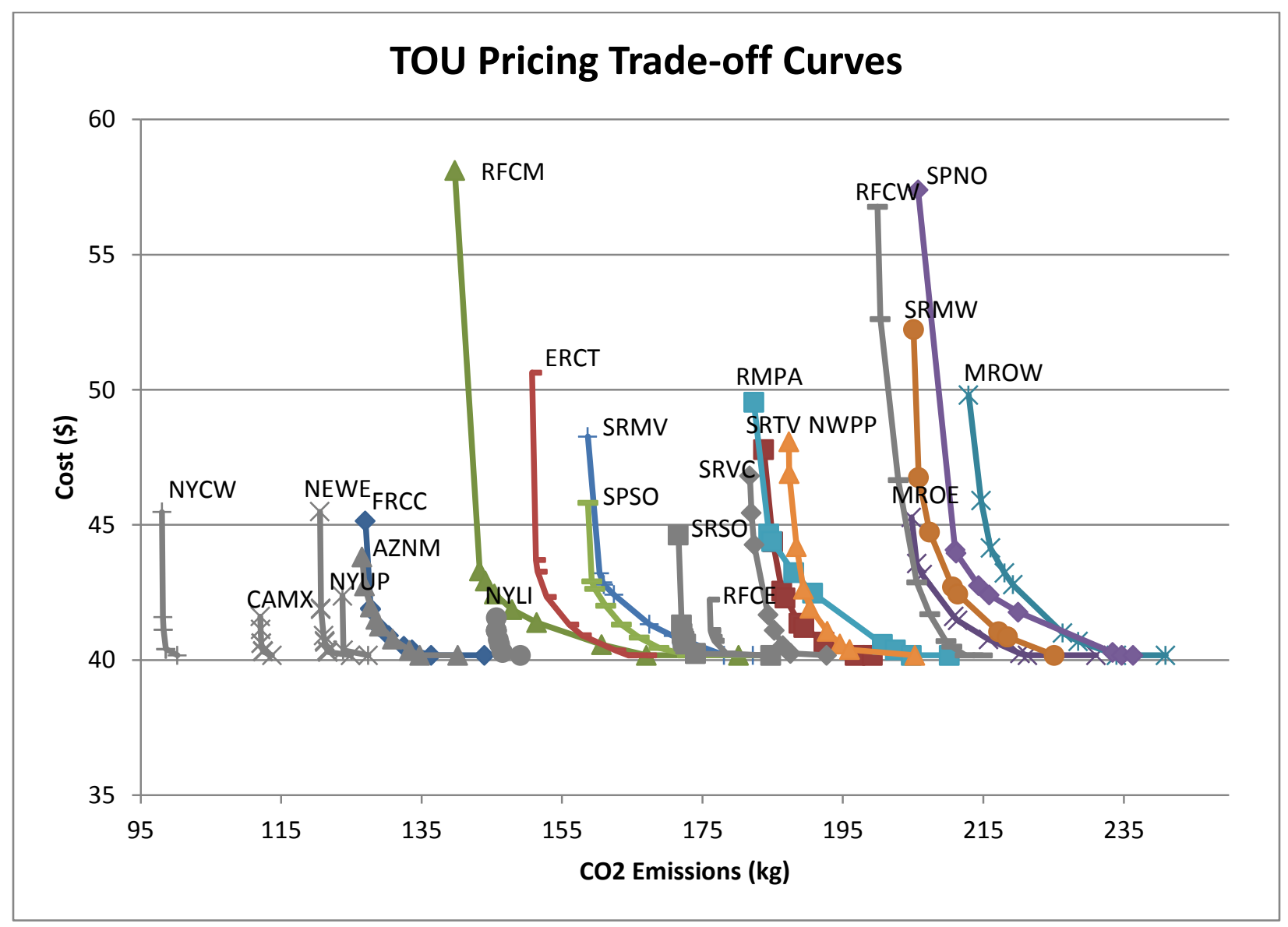

Figure 5: Multi-objective results using TOU pricing.

The $y$-axis shows the cost of electricity to the customer for the week. The $\mathrm{x}$-axis shows the $\mathrm{CO}_{2}$ emissions from the generation of the electricity the house consumed over the week. 


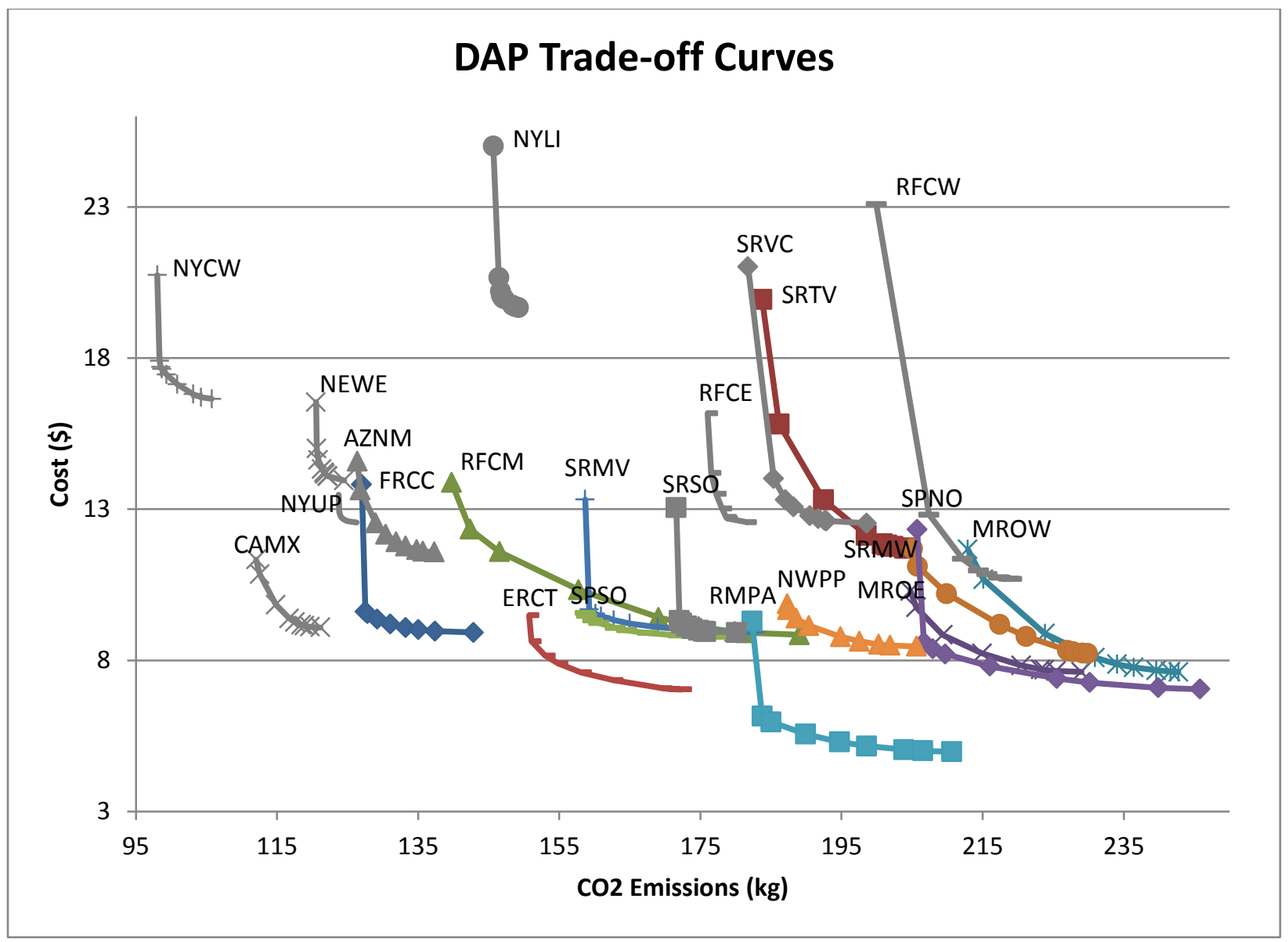

Figure 6: Multi-objective results using DAP.

The $y$-axis shows the cost of electricity to the customer for the week. The $\mathrm{x}$-axis shows the $\mathrm{CO}_{2}$ emissions from the generation of the electricity the house consumed over the week.

Figure 7 is similar to Figure 6 except the weekend price data for FRCC, SRMV, SPSO, SPNO, and RMPA was substituted with the data from the prior weekend. This was done because these regions used price data from Southwest Power Pool which contained abnormally high prices for two of the weekend hours. 


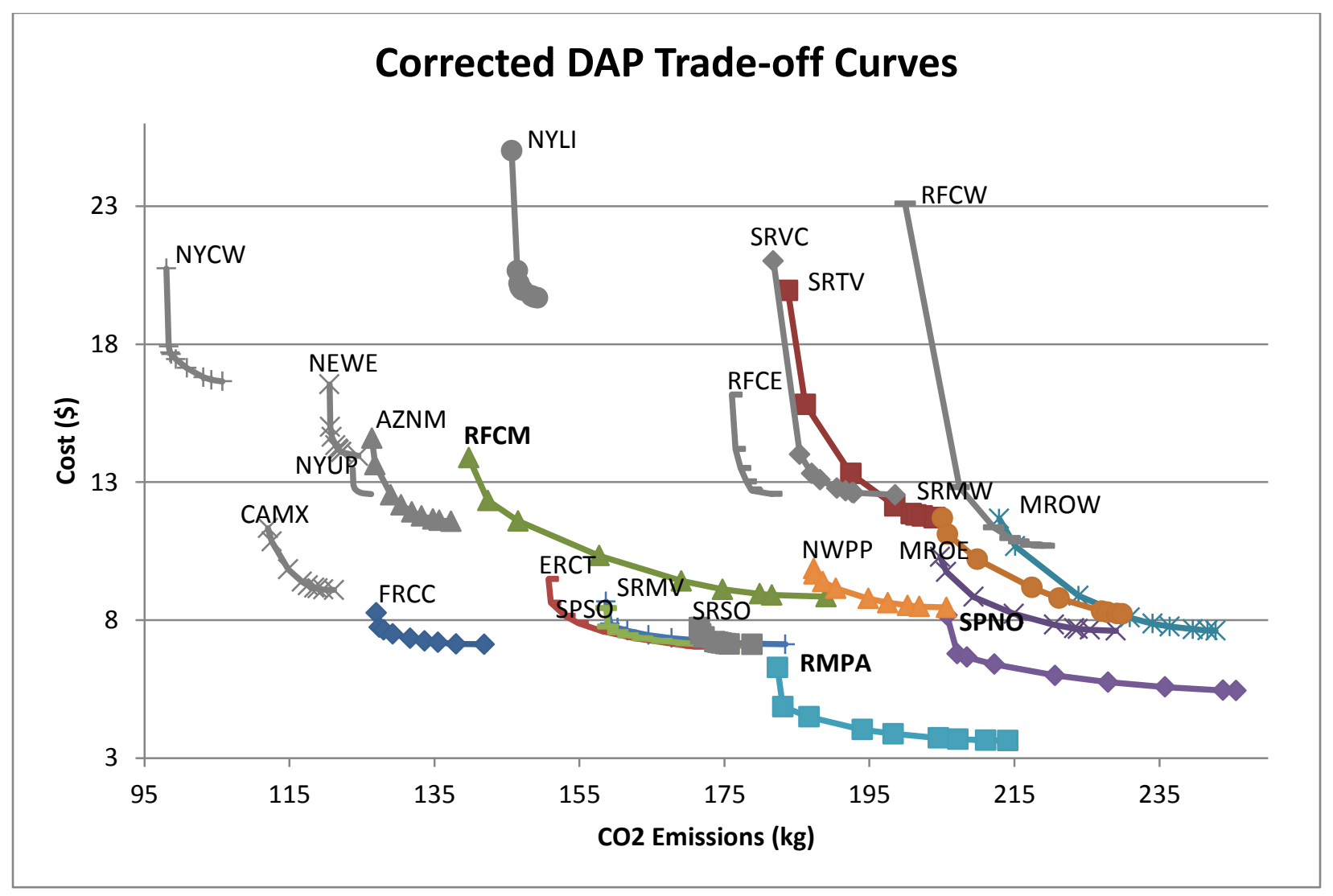

Figure 7: Multi-objective results using corrected DAP.

The $y$-axis shows the cost of electricity to the customer for the week. The $\mathrm{x}$-axis shows the $\mathrm{CO}_{2}$ emissions from the generation of the electricity the house consumed over the week. Bold labels are highlighting some of the more favorable trade-off curves.

The multi-objective model produced a variety of schedules for each region each which provide varying amounts of cost and emissions reduction. The reason for a customer to use a battery energy storage system is to reduce their electricity bill so the most favorable schedules would be ones in which the sacrificed cost reductions are small but the reduction in emissions from the single objective (cost) model is significant. Looking at Figure 7 the regions with favorable curves are ones like RMPA, SPNO, and RFCM (these regions have bolded labels) because they span a long distance on the $x$-axis (emissions) and they increase by relatively small intervals on the $y$-axis (cost) at the right side of the curves. This means that they can provide comparable savings to the single objective model while causing significantly less $\mathrm{CO}_{2}$ emissions. One curve in Figure 6 that is rather poor compared to the others is SRTV due to its steep slope which indicates that the system cannot create a large decrease in emissions without sacrificing a significant portion of the cost reduction it provides. 
More data concerning the trade-off curve for RFCM is presented in Tables 5 and 6; similar tables for the other regions are included in the supplementary data. The entry in the tables with zero for both of the weights is the baseline which shows the costs and emissions if a battery energy storage system is not used. The entry where emissions have a weight of 100 shows results of the single objective model which minimized emissions. The entry where cost has a weight of 100 shows results of the single objective model which minimized cost. All other entries show results from the multi-objective optimization. Note in Table 5 when cost has a weight of 90 the increase in emissions from using the storage system can be significantly reduced without sacrificing any of the cost reduction provided and the additional emissions can be almost entirely eliminated while sacrificing less than $3 \%$ in cost reduction when cost has a weight of 70 .

Table 5: RFCM TOU pricing trade-off curve data.

\begin{tabular}{|c|c|c|c|c|c|}
\hline \multicolumn{2}{|c|}{ Weight } & \multicolumn{2}{|c|}{ \% Reduction } & \multirow{2}{*}{$\begin{array}{l}\text { Amount } \\
\text { Billed (\$) }\end{array}$} & \multirow{2}{*}{$\begin{array}{c}\mathrm{CO} 2 \\
\text { Emittec } \\
(\mathrm{kg})\end{array}$} \\
\hline Cost & Emissions & Cost & Emissions & & \\
\hline 0 & 0 & $0 \%$ & $0 \%$ & 46.23 & 150.61 \\
\hline 0 & 100 & $-25.7 \%$ & $7.2 \%$ & 58.12 & 139.75 \\
\hline 30 & 70 & $6.4 \%$ & $4.9 \%$ & 43.29 & 143.28 \\
\hline 40 & 60 & $7.1 \%$ & $4.3 \%$ & 42.92 & 144.07 \\
\hline 50 & 50 & $8.2 \%$ & $3.5 \%$ & 42.44 & 145.41 \\
\hline 60 & 40 & $9.4 \%$ & $1.8 \%$ & 41.87 & 147.89 \\
\hline 70 & 30 & $10.5 \%$ & $-0.5 \%$ & 41.39 & 151.38 \\
\hline 80 & 20 & $12.2 \%$ & $-6.7 \%$ & 40.57 & 160.63 \\
\hline 90 & 10 & $13.1 \%$ & $-10.9 \%$ & 40.17 & 167.03 \\
\hline 100 & 0 & $13.1 \%$ & $-19.6 \%$ & 40.17 & 180.18 \\
\hline
\end{tabular}

With DAP data the model provides higher percentage reduction in cost but also causes higher percentage increases in emissions. When emissions are weighted higher than cost the model provides poor cost reduction. However with a weight of 50-50 the increased emissions are reduced by about half while only sacrificing $5 \%$ in cost reduction. 
Table 6: RFCM DAP trade-off curve data.

\begin{tabular}{|c|c|c|c|c|c|}
\hline \multicolumn{2}{|c|}{ Weight } & \multicolumn{2}{|c|}{ \% Reduction } & \multirow{2}{*}{$\begin{array}{l}\text { Amount } \\
\text { Billed }(\$)\end{array}$} & \multirow{2}{*}{$\begin{array}{c}\mathrm{CO} 2 \\
\text { Emitted } \\
(\mathrm{kg})\end{array}$} \\
\hline Cost & Emissions & Cost & Emissions & & \\
\hline 0 & 0 & $0 \%$ & $0 \%$ & 11.55 & 150.61 \\
\hline 0 & 100 & $-20.3 \%$ & $7.2 \%$ & 13.89 & 139.75 \\
\hline 20 & 80 & $-6.8 \%$ & $5.5 \%$ & 12.34 & 142.37 \\
\hline 30 & 70 & $-0.4 \%$ & $2.7 \%$ & 11.59 & 146.53 \\
\hline 40 & 60 & $10.5 \%$ & $-4.7 \%$ & 10.33 & 157.73 \\
\hline 50 & 50 & $18.4 \%$ & $-12.3 \%$ & 9.42 & 169.07 \\
\hline 60 & 40 & $21.1 \%$ & $-16.0 \%$ & 9.11 & 174.73 \\
\hline 70 & 30 & $22.5 \%$ & $-19.4 \%$ & 8.95 & 179.87 \\
\hline 80 & 20 & $22.8 \%$ & $-20.6 \%$ & 8.91 & 181.57 \\
\hline 100 & 0 & $23.4 \%$ & $-25.5 \%$ & 8.85 & 189.04 \\
\hline
\end{tabular}

RFCM was a region with some of the most favorable trade-offs between cost and emissions reductions, the other regions tested either had comparable or less favorable trade-offs. Figures 8 and 9 help to better understand what makes regions like RFCM more suitable than other regions for using the multiobjective optimization by showing how the cost of electricity and the MEFs change over time and with respect to one another.

Figures 8 and 9 show the price of electricity and the MEF each hour for the first 48 hours of the week in RFCM with TOU and day-ahead prices. They also show the initial electricity demand (D0), the demand when using the battery storage system with the single objective of cost (D100-0), and the demand when using the multi-objective model with cost weighted 0.9 and emissions weighted 0.1 (D90-10) for TOU prices and with cost and emissions weighted at 0.5 (D50-50) for DAP. With TOU prices, when the single objective model is used the battery charges at the beginning of the low price period when marginal emissions are high, the multi-objective model shifts the charging to the end of the low price period when the marginal emissions start to decrease. This reduces the increased emissions from using the system by almost half while maintaining the same cost reductions. 


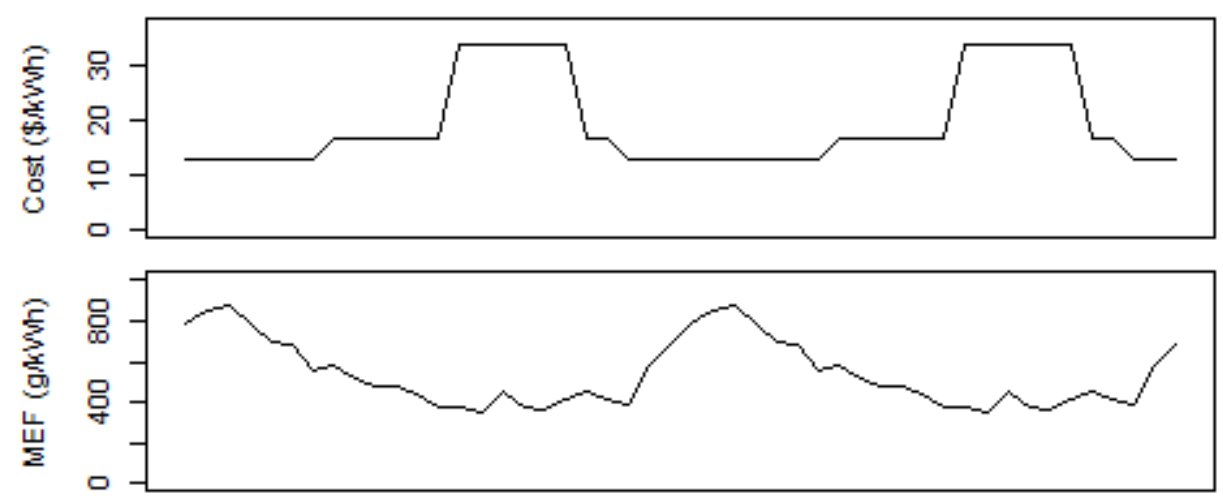

(a)

(b)

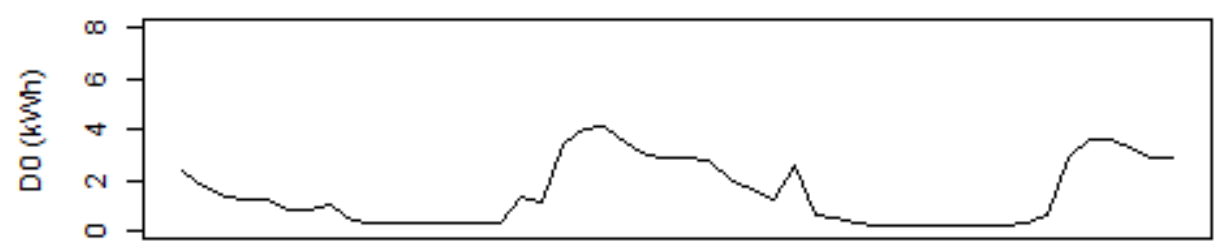

(c)

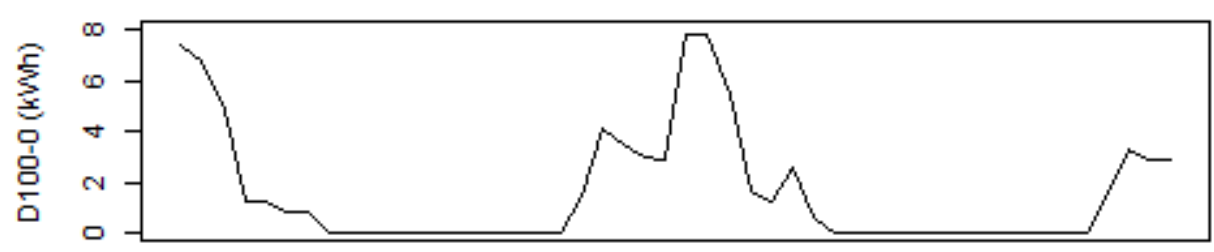

(d)

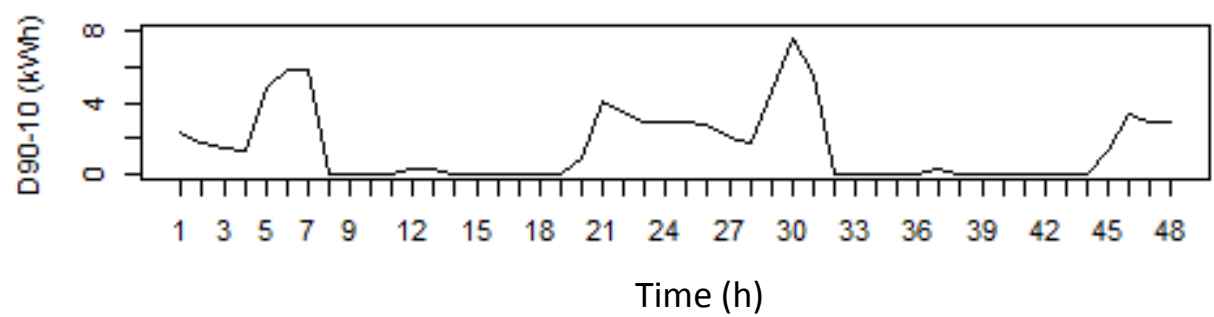

(e)

Figure 8: Cost, MEF, and electricity demand for RFCM using TOU pricing.

Data is from the first 48 hours of the week which starts on a Monday. Cost is in dollars (\$), MEF is in grams of $\mathrm{CO}_{2}$ per kilowatt hour (g/kWh), and Demands are in kilowatt hours (kWh). (a) Shows the price of electricity over time, (b) shows the MEF at each hour, (c) is the electricity demand of the household when no BESS is in use, (d) shows the electricity demand of the household when using the cost-only schedule, and (e) shows the electricity demand of the household when using the cut-off point schedule from the multi-objective optimization.

Similarly to the TOU pricing the multi-objective model using DAP shifts the charging time to later in the day when MEFs are lower. The schedule also charges the battery towards the end of the day at a point where cost and marginal emissions are low in order to reduce demand at a later hour with high emissions. This schedule reduced increased emissions by half while sacrificing $5 \%$ in cost reductions. 


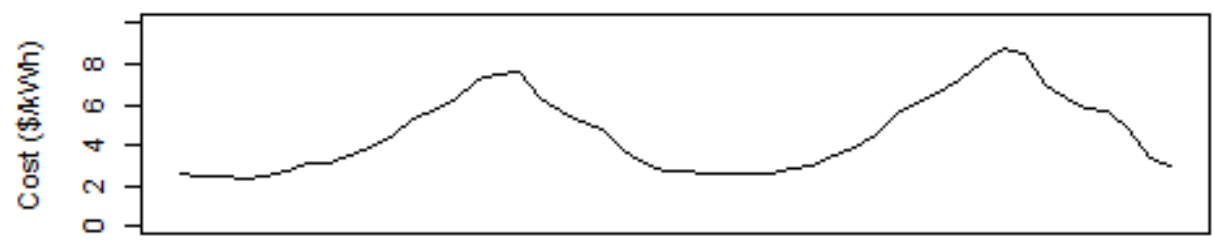

(a)

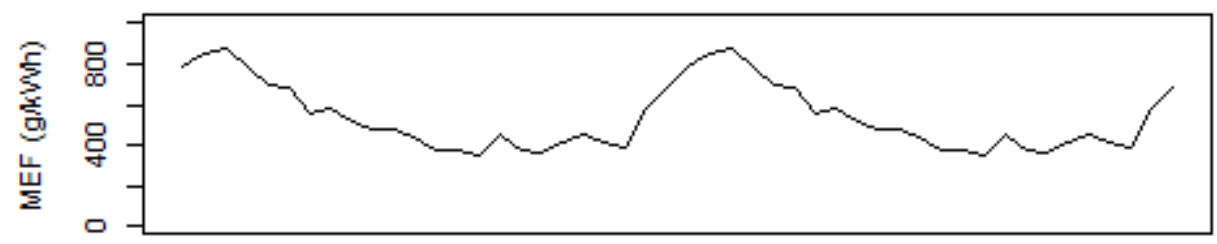

(b)



(c)

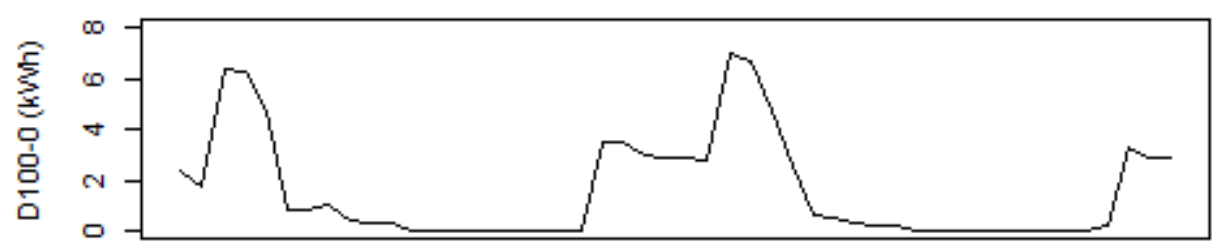

(d)

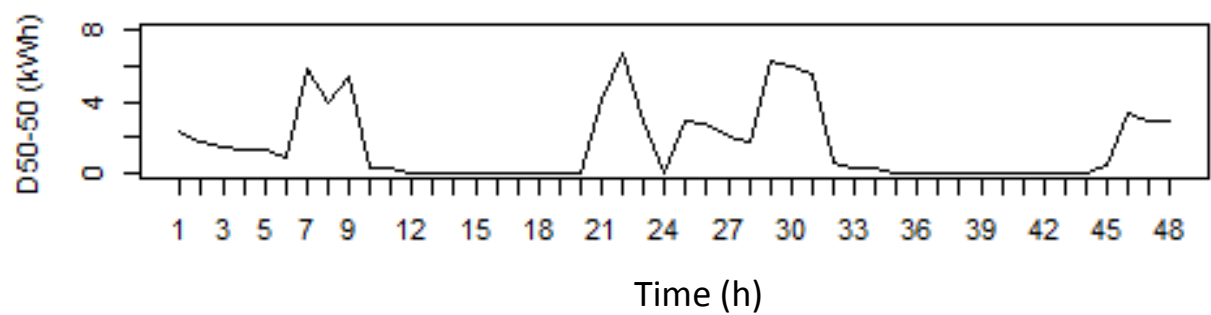

(e)

Figure 9: Cost, MEF, and Electricity Demand for RFCM using DAP.

Data is from the first 48 hours of the week which starts on a Monday. Cost is in dollars (\$), MEF is in grams of $\mathrm{CO}_{2}$ per kilowatt hour (g/kWh), and Demands are in kilowatt hours (kWh). (a) Shows the price of electricity over time, (b) shows the MEF at each hour, (c) is the electricity demand of the household when no BESS is in use, (d) shows the electricity demand of the household when using the cost-only schedule, and (e) shows the electricity demand of the household when using the cut-off point schedule from the multi-objective optimization. 


\subsection{Sensitivity Analysis}

Sensitivity analysis was performed to measure the effects on the model results of altering parameters of the battery including efficiency, capacity, and charge rate. The analysis used data from RFCM with dayahead pricing. The results are presented in Figures 10, 11, and 12.

Battery efficiencies of $60-100 \%$ were tested at $5 \%$ intervals. Higher efficiencies lower the $\mathrm{CO} 2$ emissions from the system and provide comparable cost reduction.

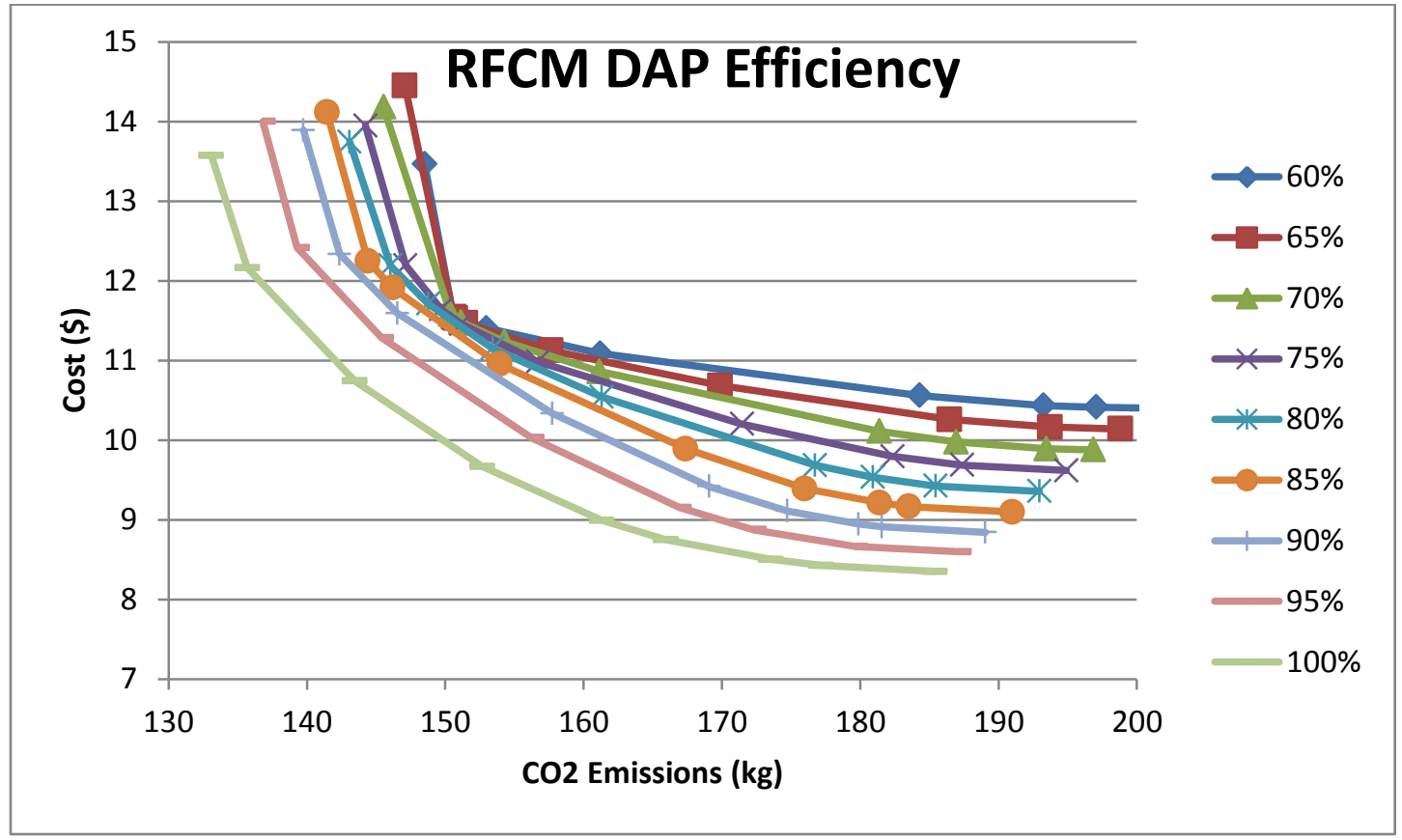

Figure 10: Sensitivity analysis of battery efficiency for the RFCM region.

The $y$-axis shows the cost of electricity to the customer for the week. The $\mathrm{x}$-axis shows the $\mathrm{CO}_{2}$ emissions from the generation of the electricity the house consumed over the week.

Battery capacities of 5-50kWh were tested at $5 \mathrm{kWh}$ intervals. As capacity is increased it extends both ends of the curve which means the system can further reduce emissions or cost but reducing emissions further increases costs and reducing costs further will increase emissions. 


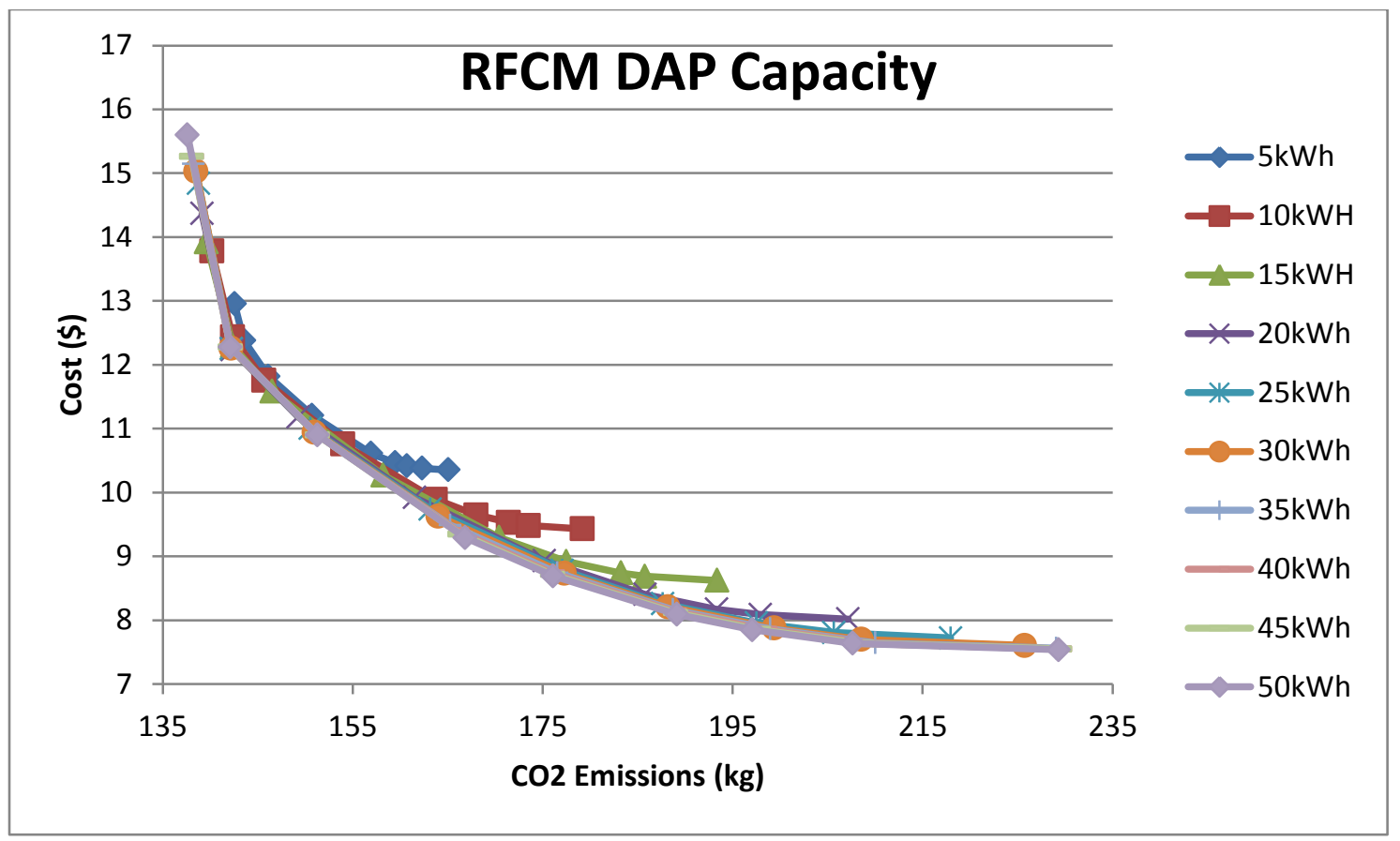

Figure 11: Sensitivity analysis of battery capacity for the RFCM region.

The $y$-axis shows the cost of electricity to the customer for the week. The $\mathrm{x}$-axis shows the $\mathrm{CO}_{2}$ emissions from the generation of the electricity the house consumed over the week.

Four separate charge rates were tested. Higher charge rates provide lower emissions at the same cost on parts of the curve but the difference is small. 




Figure 12: Sensitivity analysis of battery charge rate for the RFCM region.

The $y$-axis shows the cost of electricity to the customer for the week. The $\mathrm{x}$-axis shows the $\mathrm{CO}_{2}$ emissions from the generation of the electricity the house consumed over the week.

\section{Discussion}

This section contains an analysis of the following subjects: differences between TOU pricing and DAP, determining which regions have the best trade-offs between cost and $\mathrm{CO} 2$ emissions, and the impact of the multi-objective schedule on the BESS peak demand reduction capabilities. A perspective on the potential quantity of $\mathrm{CO}_{2}$ that can be emitted if the schedule only accounts for cost is also presented in this section. This section ends with conclusions about the significant findings of this work and identifying further research possibilities that can expand on this work.

\subsection{TOU vs DAP}

The percentage cost reduction from the cost only model was higher when using DAP in all regions except for FRCC, SRMV, SPSO, SRSO, NWPP and CAMX. The increase in emissions from using the cost only model was higher when using DAP in almost two thirds of the regions. This means that for over a third of the regions TOU pricing yielded lower cost reduction and higher $\mathrm{CO}_{2}$ emissions than DAP. For 
the remaining regions the cost reduction was not as high with TOU pricing as it was with DAP, but the increase in emissions was lower.

There was one benefit to using TOU pricing over DAP when using the multi-objective model. In some regions the multi-objective model produced a schedule that significantly reduced additional $\mathrm{CO}_{2}$ emissions with little or no impact on the cost reductions. This was possible with TOU pricing because the charging time of the battery could be moved to later in the night without the cost of electricity increasing. However this benefit may not outweigh the benefit of higher cost reductions that can be achieved using DAP in most regions.

\subsection{Trade-off Potential}

Regions with favorable trade-offs have a low cost per unit of additional $\mathrm{CO}_{2}$ reduced. Table 4 presented a ratio for each region of cost per kilogram of emissions reduced. These ratios are based on the end points of the trade-off curves and only give a general idea of a region's potential for having a favorable trade-off curve. Since the trade-off curves are not linear the cost per unit of $\mathrm{CO}_{2}$ reduced is constantly changing, for most of the regions tested the cost is lowest when $\mathrm{CO}_{2}$ levels are the highest and the cost continuously increases as the $\mathrm{CO}_{2}$ emissions are reduced. The trade-off potential in a region can be better understood by determining the point in the trade-off curve at which the cost of any additional reduction in emissions is higher than a designated $\mathrm{CO}_{2}$ price; this point will be referred to as the cut-off point. In order to do this the cost per unit of $\mathrm{CO}_{2}$ must be calculated at the individual points in the

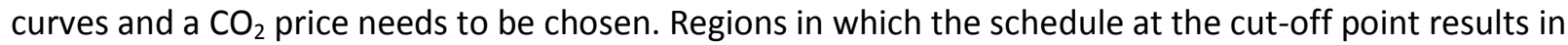
the largest amount of $\mathrm{CO}_{2}$ emissions reduction compared to the cost-only model will be considered to have the most favorable trade-off.

A report by Synapse Energy [36] presents forecasts for the price of $\mathrm{CO}_{2}$ starting in the year 2020. The report offers a low, medium, and high case forecast with the prices starting in 2020 ranging from $\$ 15$ to $\$ 25$ per ton with a levelized price from 2020 to 2050 of $\$ 26$ to $\$ 52$ per ton. The $\$ 25$ per ton value will be used to evaluate the cut-off point for each region; the point with a cost per unit of $\mathrm{CO}_{2}$ closest to $\$ 25$ per ton without going over will be designated as the cut-off point. Regions in which the most emissions can be reduced at a cost per unit of $\mathrm{CO}_{2}$ under $\$ 25$ per ton will be considered to have the best potential trade-offs. Table 7 contains information on the price per ton of $\mathrm{CO}_{2}$ at each point in the trade-off curve 
for each region using DAP as well as the kilograms of $\mathrm{CO}_{2}$ that are being reduced compared to the costonly schedule.

The dollar per ton values in Table 7 were calculated using Equation 8:

$$
\frac{\left(m_{n}-m_{C}\right)}{\left(o_{C}-o_{n}\right)} \times \frac{907.185 k g}{t o n}=P_{n}
$$

Where $m_{n}$ is the amount billed $(\$)$ at point $n$ in the trade-off curve, $m_{c}$ is the amount billed $(\$)$ from the cost optimization, $o_{C}$ is the emissions produced $(\mathrm{kg})$ from the cost optimization, $\mathrm{o}_{\mathrm{n}}$ is the emissions produced $(\mathrm{kg})$ at point $\mathrm{n}$ in the trade-off curve, and $\mathrm{P}_{\mathrm{n}}$ is a price of reducing $\mathrm{CO}_{2}$ emissions in dollars per ton at point $\mathrm{n}$ in the trade-off curve.

The cut-off point for each region in Table 7 is in bold. Having a higher number of points between the cost-only point and the cut-off point is favorable because it provides a greater variety of schedules to choose from. Regions with the highest number of points under the cut-off point were SRMV, SPSO, and RMPA. Regions such as ERCT, SRMW, and SRTV could only provide a small amount of $\mathrm{CO}_{2}$ reduction without the cost going over $\$ 25 /$ ton. The regions NEWE, NYUP, NYLI, NYCW, and RFCE could not provide any $\mathrm{CO}_{2}$ reductions for less than $\$ 25 /$ ton. More information on the cut-off points is presented in Figure 13. 
Table 7: Cost of reducing $\mathrm{CO}_{2}$ emissions using the multi-objective model compared to the cost-only model.

\begin{tabular}{|c|c|c|c|c|}
\hline Region & $\begin{array}{c}\text { Cost } \\
\text { Weight }\end{array}$ & $\begin{array}{c}\text { Emissions } \\
\text { Weight }\end{array}$ & $\begin{array}{l}\$ / \text { ton } \\
\mathrm{CO}_{2}\end{array}$ & $\begin{array}{l}\text { Additional } \\
\mathrm{CO}_{2} \\
\text { reduced } \\
(\mathrm{kg})\end{array}$ \\
\hline FRCC & $\begin{array}{r}0 \\
20 \\
30 \\
40 \\
50 \\
60 \\
70 \\
80\end{array}$ & $\begin{array}{r}100 \\
80 \\
70 \\
60 \\
50 \\
40 \\
30 \\
20\end{array}$ & $\begin{array}{r}280.12 \\
40.86 \\
37.39 \\
29.46 \\
21.57 \\
14.96 \\
11.06 \\
6.55\end{array}$ & $\begin{array}{r}15.85 \\
15.35 \\
15.05 \\
13.65 \\
11.79 \\
9.62 \\
7.80 \\
5.45\end{array}$ \\
\hline FRCC* & $\begin{array}{r}0 \\
20 \\
30 \\
40 \\
50 \\
60 \\
70 \\
80\end{array}$ & $\begin{array}{r}100 \\
80 \\
70 \\
60 \\
50 \\
40 \\
30 \\
20\end{array}$ & $\begin{array}{r}69.96 \\
38.52 \\
33.99 \\
27.36 \\
19.24 \\
13.44 \\
9.46 \\
3.97\end{array}$ & $\begin{array}{r}14.86 \\
14.47 \\
13.85 \\
12.61 \\
10.21 \\
8.22 \\
6.39 \\
3.86\end{array}$ \\
\hline SRTV & $\begin{array}{r}0 \\
10 \\
20 \\
30 \\
40 \\
50 \\
60 \\
70\end{array}$ & $\begin{array}{r}100 \\
90 \\
80 \\
70 \\
60 \\
50 \\
40 \\
30\end{array}$ & $\begin{array}{r}367.57 \\
208.54 \\
125.45 \\
70.72 \\
41.90 \\
36.44 \\
31.58 \\
20.97\end{array}$ & $\begin{array}{r}20.32 \\
17.89 \\
11.60 \\
5.53 \\
3.28 \\
2.64 \\
1.75 \\
0.11\end{array}$ \\
\hline
\end{tabular}




\begin{tabular}{|c|c|c|c|c|}
\hline Region & $\begin{array}{c}\text { Cost } \\
\text { Weight }\end{array}$ & $\begin{array}{c}\text { Emissions } \\
\text { Weight }\end{array}$ & $\begin{array}{l}\$ / \text { ton } \\
\mathrm{CO}_{2}\end{array}$ & $\begin{array}{l}\text { Additional } \\
\mathrm{CO}_{2} \\
\text { reduced } \\
(\mathrm{kg})\end{array}$ \\
\hline RFCM & $\begin{array}{r}0 \\
20 \\
30 \\
40 \\
50 \\
60 \\
70 \\
80\end{array}$ & $\begin{array}{r}100 \\
80 \\
70 \\
60 \\
50 \\
40 \\
30 \\
20\end{array}$ & $\begin{array}{r}92.84 \\
67.85 \\
58.63 \\
43.16 \\
26.09 \\
16.96 \\
10.25 \\
8.07\end{array}$ & $\begin{array}{r}49.29 \\
46.67 \\
42.51 \\
31.31 \\
19.97 \\
14.31 \\
9.17 \\
7.47\end{array}$ \\
\hline MROE & $\begin{array}{r}0 \\
10 \\
20 \\
30 \\
40 \\
50 \\
60 \\
70\end{array}$ & $\begin{array}{r}100 \\
90 \\
80 \\
70 \\
60 \\
50 \\
40 \\
30\end{array}$ & $\begin{array}{r}99.92 \\
82.44 \\
56.47 \\
39.42 \\
22.81 \\
13.25 \\
11.50 \\
8.07\end{array}$ & $\begin{array}{r}24.24 \\
23.41 \\
19.64 \\
14.09 \\
8.55 \\
5.77 \\
5.23 \\
3.56\end{array}$ \\
\hline MROW & $\begin{array}{r}0 \\
10 \\
20 \\
30 \\
40 \\
50 \\
60 \\
70\end{array}$ & $\begin{array}{r}100 \\
90 \\
80 \\
70 \\
60 \\
50 \\
40 \\
30\end{array}$ & $\begin{array}{r}123.27 \\
100.41 \\
60.71 \\
36.41 \\
26.56 \\
21.12 \\
15.03 \\
7.61\end{array}$ & $\begin{array}{r}29.83 \\
27.61 \\
18.90 \\
11.81 \\
8.66 \\
6.33 \\
3.12 \\
1.07\end{array}$ \\
\hline
\end{tabular}




\begin{tabular}{|c|c|c|c|c|}
\hline Region & $\begin{array}{c}\text { Cost } \\
\text { Weight }\end{array}$ & $\begin{array}{c}\text { Emissions } \\
\text { Weight }\end{array}$ & $\begin{array}{l}\$ / \text { ton } \\
\mathrm{CO}_{2}\end{array}$ & $\begin{array}{l}\text { Additional } \\
\qquad \mathrm{CO}_{2} \\
\text { reduced } \\
(\mathrm{kg})\end{array}$ \\
\hline & & & & \\
\hline \multirow{8}{*}{ SRMW } & 0 & 100 & 127.15 & 24.79 \\
\hline & 10 & 90 & 108.93 & 24.07 \\
\hline & 20 & 80 & 90.10 & 19.95 \\
\hline & 25 & 75 & 70.21 & 12.43 \\
\hline & 30 & 70 & 59.33 & 8.69 \\
\hline & 40 & 60 & 33.06 & 2.82 \\
\hline & 50 & 50 & 27.71 & 2.03 \\
\hline & 60 & 40 & 19.55 & 0.68 \\
\hline \multirow{9}{*}{ SRMV } & 0 & 100 & 16550 & 211 \\
\hline & 0 & 100 & 105.38 & 24.11 \\
\hline & 20 & 80 & 29.50 & 23.55 \\
\hline & 30 & 70 & 24.78 & 22.63 \\
\hline & 40 & 60 & 22.41 & 21.86 \\
\hline & 50 & 50 & 18.61 & 20.06 \\
\hline & 60 & 40 & 15.15 & 17.78 \\
\hline & 70 & 30 & 11.56 & 13.82 \\
\hline & 80 & 20 & 5.42 & 6.96 \\
\hline \multirow{9}{*}{ SRMV* } & & & & \\
\hline & 0 & 100 & 56.81 & 24.73 \\
\hline & 20 & 80 & 28.07 & 24.18 \\
\hline & 30 & 70 & 23.74 & 23.14 \\
\hline & 40 & 60 & 20.66 & 21.79 \\
\hline & 50 & 50 & 16.28 & 18.90 \\
\hline & 60 & 40 & 13.13 & 15.70 \\
\hline & 70 & 30 & 9.33 & 10.73 \\
\hline & 80 & 20 & 4.32 & 5.56 \\
\hline
\end{tabular}




\begin{tabular}{|c|c|c|c|c|}
\hline Region & $\begin{array}{c}\text { Cost } \\
\text { Weight }\end{array}$ & $\begin{array}{c}\text { Emissions } \\
\text { Weight }\end{array}$ & $\begin{array}{l}\$ / \text { ton } \\
\mathrm{CO}_{2}\end{array}$ & $\begin{array}{l}\text { Additional } \\
\mathrm{CO}_{2} \\
\text { reduced } \\
(\mathrm{kg})\end{array}$ \\
\hline ERCT & $\begin{array}{r}0 \\
10 \\
20 \\
30 \\
40 \\
50 \\
60 \\
70\end{array}$ & $\begin{array}{r}100 \\
90 \\
80 \\
70 \\
60 \\
50 \\
40 \\
30\end{array}$ & $\begin{array}{r}102.74 \\
67.83 \\
52.25 \\
44.35 \\
35.64 \\
28.43 \\
12.84 \\
4.82\end{array}$ & $\begin{array}{r}21.62 \\
21.30 \\
19.35 \\
17.52 \\
14.21 \\
9.72 \\
2.71 \\
1.55\end{array}$ \\
\hline SPSO & $\begin{array}{r}0 \\
20 \\
30 \\
40 \\
50 \\
60 \\
70 \\
80\end{array}$ & $\begin{array}{r}100 \\
80 \\
70 \\
60 \\
50 \\
40 \\
30 \\
20\end{array}$ & $\begin{array}{r}36.76 \\
32.74 \\
26.92 \\
23.65 \\
17.63 \\
14.44 \\
10.98 \\
6.24\end{array}$ & $\begin{array}{r}19.38 \\
19.20 \\
18.32 \\
17.49 \\
15.09 \\
13.48 \\
10.55 \\
6.25\end{array}$ \\
\hline SPSO* & $\begin{array}{r}0 \\
20 \\
30 \\
40 \\
50 \\
60 \\
70 \\
80\end{array}$ & $\begin{array}{r}100 \\
80 \\
70 \\
60 \\
50 \\
40 \\
30 \\
20\end{array}$ & $\begin{array}{r}63.70 \\
32.74 \\
24.76 \\
20.80 \\
16.76 \\
13.09 \\
9.54 \\
5.43\end{array}$ & $\begin{array}{r}19.39 \\
19.15 \\
17.75 \\
16.38 \\
14.37 \\
11.68 \\
8.37 \\
5.05\end{array}$ \\
\hline
\end{tabular}




\begin{tabular}{|c|c|c|c|c|}
\hline Region & $\begin{array}{c}\text { Cost } \\
\text { Weight }\end{array}$ & $\begin{array}{c}\text { Emissions } \\
\text { Weight }\end{array}$ & $\begin{array}{l}\$ / \text { ton } \\
\mathrm{CO}_{2}\end{array}$ & $\begin{array}{l}\text { Additional } \\
\mathrm{CO}_{2} \\
\text { reduced } \\
\quad(\mathrm{kg})\end{array}$ \\
\hline SPNO & $\begin{array}{r}0 \\
10 \\
20 \\
30 \\
40 \\
50 \\
60 \\
70\end{array}$ & $\begin{array}{r}100 \\
90 \\
80 \\
70 \\
60 \\
50 \\
40 \\
30\end{array}$ & $\begin{array}{r}119.55 \\
35.95 \\
31.98 \\
29.24 \\
23.11 \\
15.70 \\
12.59 \\
6.49\end{array}$ & $\begin{array}{r}40.09 \\
39.12 \\
37.87 \\
36.09 \\
29.77 \\
20.28 \\
15.61 \\
5.91\end{array}$ \\
\hline SPNO* & $\begin{array}{r}0 \\
20 \\
25 \\
30 \\
40 \\
50 \\
60 \\
70\end{array}$ & $\begin{array}{r}100 \\
80 \\
75 \\
70 \\
60 \\
50 \\
40 \\
30\end{array}$ & $\begin{array}{r}62.07 \\
31.42 \\
29.56 \\
25.97 \\
19.93 \\
15.42 \\
12.00 \\
3.80\end{array}$ & $\begin{array}{r}39.87 \\
38.46 \\
37.15 \\
33.35 \\
24.96 \\
17.67 \\
9.79 \\
1.83\end{array}$ \\
\hline RMPA & $\begin{array}{r}0 \\
10 \\
20 \\
30 \\
40 \\
50 \\
60 \\
70\end{array}$ & $\begin{array}{r}100 \\
90 \\
80 \\
70 \\
60 \\
50 \\
40 \\
30\end{array}$ & $\begin{array}{r}138.34 \\
39.94 \\
35.00 \\
25.49 \\
18.47 \\
14.41 \\
9.22 \\
6.73\end{array}$ & $\begin{array}{r}28.32 \\
26.90 \\
25.63 \\
20.71 \\
15.91 \\
12.06 \\
6.81 \\
4.12\end{array}$ \\
\hline
\end{tabular}




\begin{tabular}{|c|c|c|c|c|}
\hline Region & $\begin{array}{c}\text { Cost } \\
\text { Weight }\end{array}$ & $\begin{array}{c}\text { Emissions } \\
\text { Weight }\end{array}$ & $\begin{array}{l}\$ / \text { ton } \\
\mathrm{CO}_{2}\end{array}$ & $\begin{array}{l}\text { Additional } \\
\qquad \mathrm{CO}_{2} \\
\text { reduced } \\
\quad(\mathrm{kg})\end{array}$ \\
\hline & & & & \\
\hline \multirow{8}{*}{ RMPA* } & 0 & 100 & 75.72 & 31.77 \\
\hline & 10 & 90 & 35.90 & 31.03 \\
\hline & 20 & 80 & 28.46 & 27.42 \\
\hline & 30 & 70 & 18.09 & 20.08 \\
\hline & 40 & 60 & 14.10 & 15.80 \\
\hline & 50 & 50 & 9.20 & 9.57 \\
\hline & 60 & 40 & 7.08 & 6.87 \\
\hline & 70 & 30 & 3.58 & 3.04 \\
\hline \multirow{9}{*}{ NWPP } & & & & \\
\hline & 0 & 100 & 69.56 & 18.34 \\
\hline & 10 & 90 & 60.05 & 18.25 \\
\hline & 20 & 80 & 49.48 & 17.08 \\
\hline & 30 & 70 & 40.86 & 15.27 \\
\hline & 40 & 60 & 26.91 & 10.79 \\
\hline & 50 & 50 & 19.05 & 8.10 \\
\hline & 60 & 40 & 11.44 & 5.38 \\
\hline & 70 & 30 & 7.48 & 3.73 \\
\hline \multirow{9}{*}{ NEWE } & & & & \\
\hline & 0 & 100 & 589.17 & 3.99 \\
\hline & 5 & 95 & 246.11 & 3.88 \\
\hline & 10 & 90 & 170.10 & 3.64 \\
\hline & 20 & 80 & 110.01 & 3.13 \\
\hline & 25 & 75 & 84.32 & 2.84 \\
\hline & 30 & 70 & 73.63 & 2.68 \\
\hline & 35 & 65 & 56.18 & 2.38 \\
\hline & 40 & 60 & 54.46 & 2.35 \\
\hline
\end{tabular}




\begin{tabular}{|c|c|c|c|c|}
\hline Region & $\begin{array}{c}\text { Cost } \\
\text { Weight }\end{array}$ & $\begin{array}{c}\text { Emissions } \\
\text { Weight }\end{array}$ & $\begin{array}{l}\$ / \text { ton } \\
\mathrm{CO}_{2}\end{array}$ & $\begin{array}{l}\text { Additional } \\
\mathrm{CO}_{2} \\
\text { reduced } \\
(\mathrm{kg})\end{array}$ \\
\hline \multirow{8}{*}{ NYUP } & 0 & 100 & 325.56 & 2.55 \\
\hline & 10 & 90 & 122.58 & 2.44 \\
\hline & 20 & 80 & 80.88 & 2.25 \\
\hline & 30 & 70 & 68.26 & 2.13 \\
\hline & 40 & 60 & 51.19 & 1.87 \\
\hline & 50 & 50 & 35.70 & 1.44 \\
\hline & 60 & 40 & 29.99 & 1.27 \\
\hline & 70 & 30 & 25.40 & 0.99 \\
\hline \multirow{8}{*}{ NYLI } & 0 & 100 & 1347.81 & 3.59 \\
\hline & 5 & 95 & 320.96 & 2.79 \\
\hline & 10 & 90 & 187.59 & 2.58 \\
\hline & 20 & 80 & 147.13 & 2.43 \\
\hline & 30 & 70 & 131.06 & 2.22 \\
\hline & 40 & 60 & 125.23 & 2.05 \\
\hline & 50 & 50 & 79.25 & 0.86 \\
\hline & 60 & 40 & 58.84 & 0.46 \\
\hline \multirow{8}{*}{ NYCW } & 0 & 100 & 480.83 & 7.73 \\
\hline & 10 & 90 & 154.97 & 7.40 \\
\hline & 20 & 80 & 132.46 & 7.21 \\
\hline & 30 & 70 & 126.75 & 7.07 \\
\hline & 40 & 60 & 113.76 & 6.43 \\
\hline & 50 & 50 & 89.47 & 4.90 \\
\hline & 60 & 40 & 52.80 & 2.64 \\
\hline & 70 & 30 & 32.37 & 1.52 \\
\hline
\end{tabular}




\begin{tabular}{|c|c|c|c|c|}
\hline Region & $\begin{array}{c}\text { Cost } \\
\text { Weight }\end{array}$ & $\begin{array}{c}\text { Emissions } \\
\text { Weight }\end{array}$ & $\begin{array}{l}\$ / \text { ton } \\
\mathrm{CO}_{2}\end{array}$ & $\begin{array}{l}\text { Additional } \\
\mathrm{CO}_{2} \\
\text { reduced } \\
(\mathrm{kg})\end{array}$ \\
\hline \multirow{8}{*}{ RFCE } & 0 & 100 & 590.52 & 5.54 \\
\hline & 5 & 95 & 292.36 & 5.04 \\
\hline & 10 & 90 & 196.30 & 4.34 \\
\hline & 12 & 88 & 116.09 & 3.53 \\
\hline & 15 & 85 & 51.62 & 2.91 \\
\hline & 20 & 80 & 45.54 & 2.85 \\
\hline & 30 & 70 & 41.81 & 2.78 \\
\hline & 40 & 60 & 39.20 & 2.68 \\
\hline \multirow{8}{*}{ RFCW } & 0 & 100 & 585.97 & 19.19 \\
\hline & 10 & 90 & 164.76 & 11.71 \\
\hline & 20 & 80 & 86.45 & 6.96 \\
\hline & 30 & 70 & 54.19 & 4.72 \\
\hline & 40 & 60 & 42.12 & 3.49 \\
\hline & 50 & 50 & 24.27 & 1.88 \\
\hline & 60 & 40 & 22.07 & 1.62 \\
\hline & 70 & 30 & 16.71 & 0.40 \\
\hline \multirow{8}{*}{ SRVC } & 0 & 100 & 457.59 & 16.81 \\
\hline & 10 & 90 & 101.55 & 13.17 \\
\hline & 20 & 80 & 60.89 & 11.51 \\
\hline & 30 & 70 & 47.37 & 10.36 \\
\hline & 40 & 60 & 27.48 & 8.03 \\
\hline & 50 & 50 & 19.24 & 6.83 \\
\hline & 60 & 40 & 13.13 & 5.91 \\
\hline & 70 & 30 & 12.11 & 5.68 \\
\hline
\end{tabular}




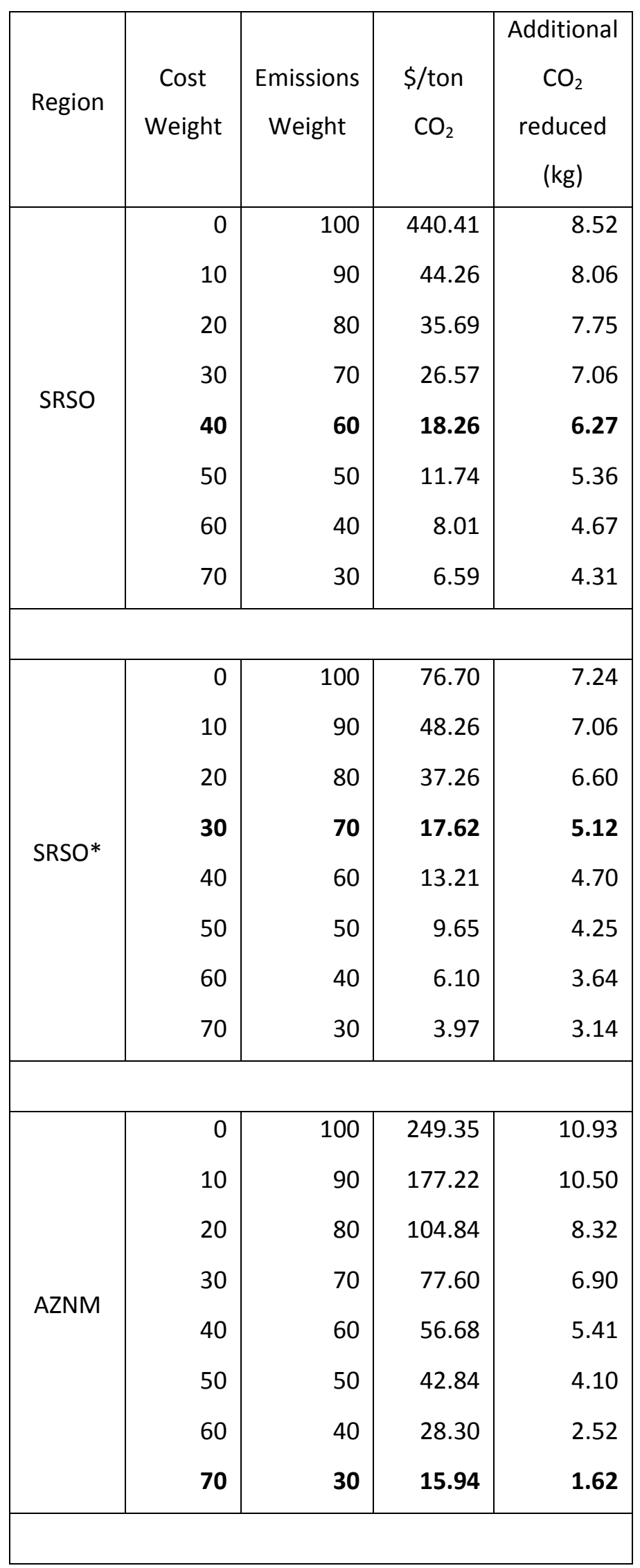




\begin{tabular}{|c|c|c|c|c|}
\hline \multirow{6}{*}{ Region } & $\begin{array}{c}\text { Cost } \\
\text { Weight }\end{array}$ & $\begin{array}{c}\text { Emissions } \\
\text { Weight }\end{array}$ & $\begin{array}{c}\text { \$/ton } \\
\mathrm{CO}_{2}\end{array}$ & $\begin{array}{c}\text { Additional } \\
\mathrm{CO}_{2} \\
\text { reduced } \\
(\mathrm{kg})\end{array}$ \\
\hline \multirow{6}{*}{ CAMX } & 0 & 100 & 223.45 & 9.10 \\
& 10 & 90 & 186.33 & 8.59 \\
& 20 & 80 & 107.78 & 6.32 \\
& 40 & 70 & 60.85 & 4.42 \\
& 50 & 50 & 43.60 & 3.59 \\
& 60 & $\mathbf{4 0}$ & $\mathbf{2 3 . 2 3}$ & $\mathbf{2 . 2 7}$ \\
& 70 & 30 & 13.54 & 1.47 \\
\hline
\end{tabular}

Figure 13 shows the $\mathrm{CO}_{2}$ emissions produced in each region using the cost-only model and using the cutoff point schedule under DAP. The difference between the two bars is the reduction in $\mathrm{CO}_{2}$ emissions achievable at the cut-off point compared to using the cost-only model. In most regions there is still a net increase in emissions using the multi-objective model but the level of emissions is significantly lower than when using the cost-only model. The regions FRCC, SRMV, SPSO, SPNO, SRSO and RMPA are using the corrected day-ahead data in this figure.

The regions in Figure 13 are listed in order of $\mathrm{CO}_{2}$ reduced compared to the cost only model. SRMV, SPSO, FRCC, SRSO, and SRVC saw a reduction in $\mathrm{CO}_{2}$ emissions compared the no battery case, RFCM was in the top five regarding reduction in $\mathrm{CO}_{2}$ but net emissions there were the highest because the cost only scenario $\mathrm{CO}_{2}$ emissions are greater there than in any other region. ERCT, CAMX, RFCW, AZNM, SRMW, and SRTV provided very little $\mathrm{CO}_{2}$ reduction at their cut-off points. The remaining regions saw a significant reduction in $\mathrm{CO}_{2}$ emissions from the cost only model but still had net emissions compared to the no battery case. Figure 14 shows a map of the regions colored based on the amount of $\mathrm{CO}_{2}$ reductions each region achieved using the multi-objective schedule. Regions in green were able to achieve the highest reductions and regions in red achieved low reductions; grey regions could not achieve any reductions at the cut-off point. 


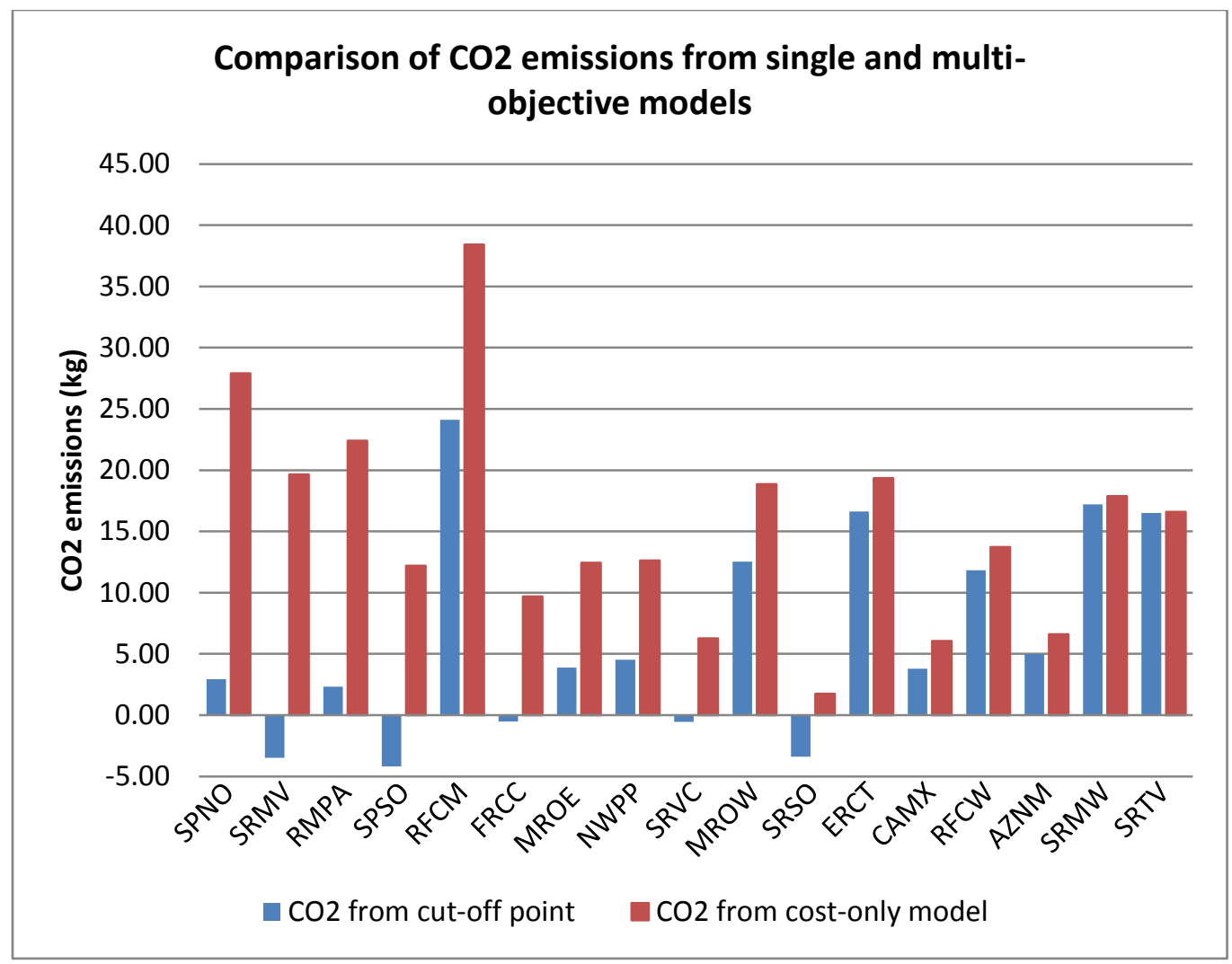

Figure 13: $\mathrm{CO}_{2}$ emissions from the cost-only model compared to the multi-objective model cut-off point schedule using DAP.

The regions are sorted by the reduction in $\mathrm{CO}_{2}$ emissions from the cut-off point compared to the cost only model from highest to lowest. This reduction is the difference between the red and blue bar for each region. 


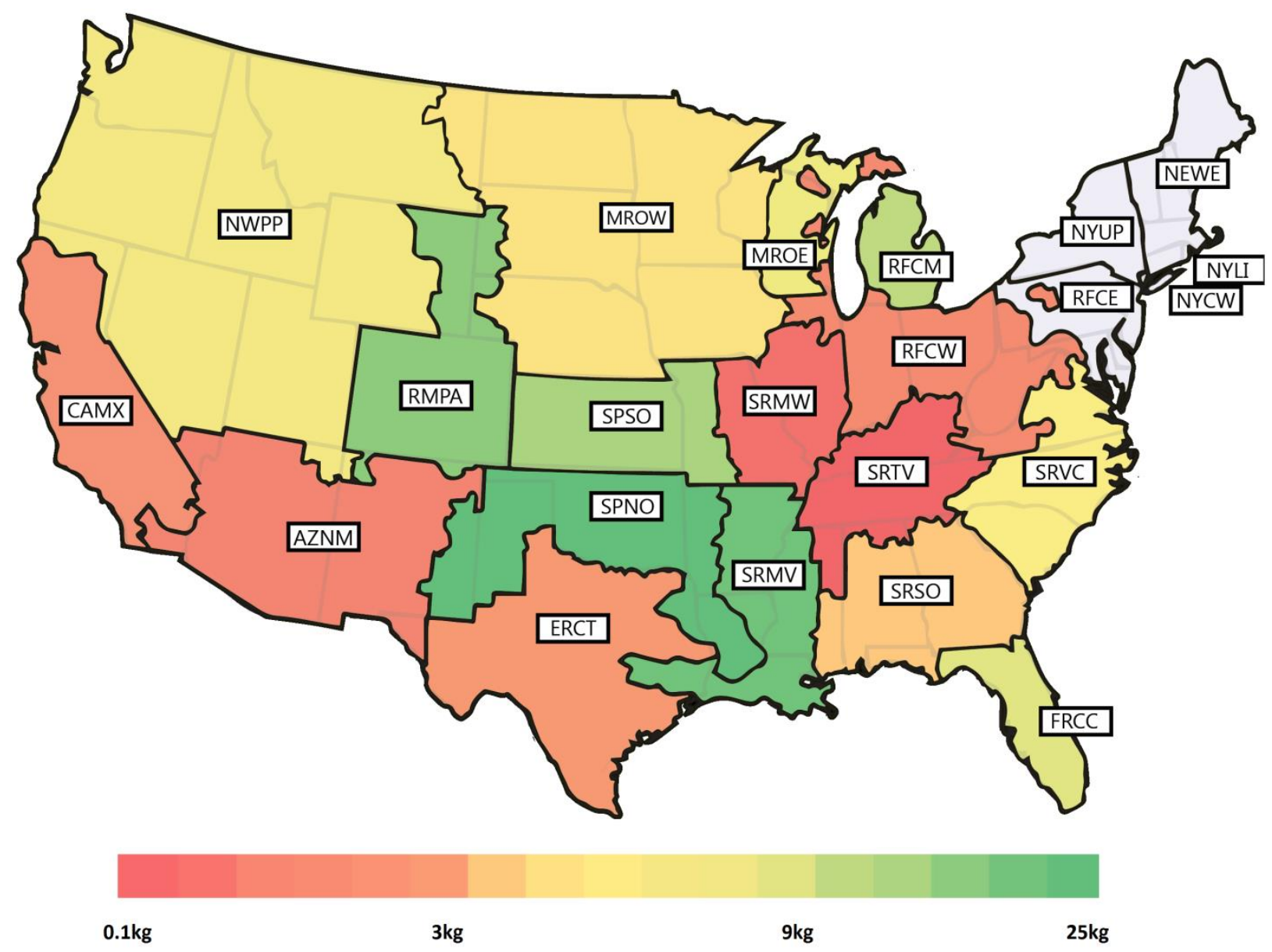

Figure 14: eGRID regions colored by $\mathrm{CO}_{2}$ reductions achievable with the multi-objective model cut-off point under DAP.

Table 8 shows the percentage cost and emissions reduction from the cost-only model using the cut-off point from the multi-objective model in each region. The regions with cut-off points that have the largest reduction in emissions significantly lower the cost reductions provided by the BESS. This would make operating a BESS with such a schedule less feasible to home owners without the presence of some sort of economic incentive. If utilities or regulators are looking to reduce $\mathrm{CO}_{2}$ emissions from the system, providing incentives for running BESSs with these multi-objective schedules could make economic sense in these regions. 
Table 8: Comparison of cost and emissions reductions under DAP provided by the cost only-model and the multi-objective model at the cut-off point.

\begin{tabular}{ccccc}
\hline \multirow{2}{*}{ Region } & \multicolumn{2}{c}{ Cost Reduction } & \multicolumn{2}{c}{$\mathrm{CO}_{2}$ reduction } \\
\cline { 2 - 5 } & Multi & $\begin{array}{c}\text { Cost } \\
\text { only }\end{array}$ & Multi & $\begin{array}{c}\text { Cost } \\
\text { only }\end{array}$ \\
\hline SPNO & $5.9 \%$ & $14.5 \%$ & $-1.4 \%$ & $-12.8 \%$ \\
SRMV & $1.4 \%$ & $9 \%$ & $2.1 \%$ & $-12 \%$ \\
RMPA & $15.5 \%$ & $23.9 \%$ & $-1.2 \%$ & $-11.7 \%$ \\
SPSO & $2.9 \%$ & $9 \%$ & $3.4 \%$ & $-7 \%$ \\
RFCM & $21.1 \%$ & $23.4 \%$ & $-16.0 \%$ & $-25.5 \%$ \\
FRCC & $6.3 \%$ & $9 \%$ & $0.4 \%$ & $-7 \%$ \\
MROE & $24.7 \%$ & $26.8 \%$ & $-1.8 \%$ & $-5.7 \%$ \\
NWPP & $10.0 \%$ & $11.8 \%$ & $-2.3 \%$ & $-6.5 \%$ \\
MROW & $25.3 \%$ & $26.8 \%$ & $-5.6 \%$ & $-8.4 \%$ \\
ERCT & $16.7 \%$ & $17.2 \%$ & $-10.9 \%$ & $-12.6 \%$ \\
SRMW & $23.8 \%$ & $24.0 \%$ & $-8.1 \%$ & $-8.4 \%$ \\
SRTV & $37.5 \%$ & $37.5 \%$ & $-8.8 \%$ & $-8.9 \%$ \\
RFCW & $34.6 \%$ & $34.9 \%$ & $-5.8 \%$ & $-6.7 \%$ \\
SRVC & $37.6 \%$ & $38.3 \%$ & $0.3 \%$ & $-3.3 \%$ \\
SRSO & $7.8 \%$ & $9.1 \%$ & $1.9 \%$ & $-1.0 \%$ \\
AZNM & $18.4 \%$ & $18.6 \%$ & $-3.8 \%$ & $-5.1 \%$ \\
CAMX & $12.4 \%$ & $12.9 \%$ & $-3.3 \%$ & $-5.3 \%$ \\
\hline
\end{tabular}

\subsection{Relationship between Grid Resource Mix and Trade-off Potential}

Households in regions in which baseload generation is associated with higher $\mathrm{CO}_{2}$ emissions than nonbaseload generation are likely to cause an increase in emissions when using a BESS. Coal and natural gas are the most used resources in the US for electricity generation and coal generates almost twice as much $\mathrm{CO}_{2}$ as natural gas [1]. For the regions in this study that had the best trade-off potentials one or more of the following was true about their coal and natural gas generation: coal is the most used 
resource for energy generation in the region, a majority of coal generation in the region is used for baseload generation, and/or a majority of natural gas generation in the region is used for non-baseload generation. Table 9 shows data from the EPA eGRID database [37] on coal and natural gas statistics for each of the eGRID regions, this data includes; the percentage of coal and natural gas used for total generation in that region, the percentage of coal generation used for baseload and for non-baseload generation, and the percentage of natural gas generation used for baseload and non-baseload generation. The regions in table 9 are listed in order of $\mathrm{CO}_{2}$ reduced at the cut-off point compared to the cost only model except for the last 5 regions which did not have a cut-off point. 
Table 9: Coal and natural gas generation percentages by region.

\begin{tabular}{|c|c|c|c|c|c|c|}
\hline \multirow[b]{2}{*}{ Region } & \multirow{2}{*}{$\begin{array}{c}\text { Coal } \\
\text { generation } \\
\text { as a } \\
\text { percentage } \\
\text { of total } \\
\text { generation }\end{array}$} & \multirow{2}{*}{$\begin{array}{c}\text { Gas } \\
\text { generation } \\
\text { as a } \\
\text { percentage } \\
\text { of total } \\
\text { generation } \\
\end{array}$} & \multicolumn{2}{|c|}{ Coal } & \multicolumn{2}{|c|}{ Gas } \\
\hline & & & $\begin{array}{c}\text { Baseload } \\
(\%)\end{array}$ & $\begin{array}{c}\text { Non- } \\
\text { baseload } \\
(\%)\end{array}$ & $\begin{array}{c}\text { Baseload } \\
(\%)\end{array}$ & $\begin{array}{c}\text { Non- } \\
\text { baseload } \\
(\%)\end{array}$ \\
\hline SPNO & 66.2 & 6.5 & 60.4 & 39.6 & 9.7 & 90.3 \\
\hline SRMV & 25.8 & 49.0 & 64.6 & 35.4 & 47.6 & 52.4 \\
\hline RMPA & 68.3 & 16.0 & 71.7 & 28.3 & 25.0 & 75.0 \\
\hline SPSO & 48.4 & 34.5 & 58.2 & 41.8 & 30.1 & 69.9 \\
\hline RFCM & 59.6 & 14.6 & 46.8 & 53.2 & 18.0 & 82.0 \\
\hline FRCC & 21.7 & 61.4 & 37.7 & 62.3 & 32.6 & 67.4 \\
\hline MROE & 71.3 & 10.5 & 46.4 & 53.6 & 8.6 & 91.4 \\
\hline NWPP & 36.2 & 11.9 & 76.4 & 23.6 & 39.3 & 60.7 \\
\hline SRVC & 31.7 & 20.8 & 57.1 & 42.9 & 30.7 & 69.3 \\
\hline MROW & 58.4 & 3.2 & 73.0 & 27.0 & 11.9 & 88.1 \\
\hline SRSO & 36.2 & 36.5 & 45.7 & 54.3 & 59.4 & 40.6 \\
\hline ERCT & 33.2 & 45.3 & 60.5 & 39.5 & 47.5 & 52.5 \\
\hline CAMX & 0.4 & 62.5 & 34.9 & 65.1 & 53.0 & 47.0 \\
\hline RFCW & 60.0 & 9.3 & 60.3 & 39.7 & 52.8 & 47.2 \\
\hline AZNM & 21.3 & 39.1 & 64.1 & 35.9 & 29.6 & 70.4 \\
\hline SRMW & 82.4 & 1.2 & 72.7 & 27.3 & 24.7 & 75.3 \\
\hline SRTV & 52.4 & 14.8 & 48.5 & 51.5 & 29.9 & 70.1 \\
\hline NEWE & 4.5 & 43.2 & 3.1 & 96.9 & 41.0 & 59.0 \\
\hline NYCW & 0.0 & 55.2 & 0.0 & 0.0 & 41.8 & 58.2 \\
\hline NYLI & 0.0 & 84.0 & 0.0 & 0.0 & 70.8 & 29.2 \\
\hline NYUP & 5.5 & 25.9 & 10.6 & 89.4 & 39.2 & 60.8 \\
\hline RFCE & 23.3 & 30.7 & 51.2 & 48.8 & 55.1 & 44.9 \\
\hline
\end{tabular}

\subsection{Impact on Peak Load Reduction:}

Using multi-objective BESS schedules will have an impact on the system's ability to contribute to peak load reduction (peak load in this case is on a regional scale rather than a household scale). Figures 15 , $16,17,18$, and 19 show the demand profiles when using the cut-off point schedule for the top five regions from Table 2; SPNO, SRMV, RMPA, SPSO, and RFCM. The figures also include the cost of 
electricity and MEF over time as well as the demand profile when no BESS is in use (DO) and when a BESS is scheduled using the cost-only model (D100-0). The time span shown in these figures is Wednesday through Friday which is when electricity prices were generally the highest. Cost is in $\$ / k W h$, MEF is in $\mathrm{g} / \mathrm{kWh}$, and demands are in kWh.

In the majority of regions the multi-objective schedules do not reduce as much demand at high price times as the cost only schedules because they instead reduced demand at hours with high MEFs. The exception to this is RFCM which achieved most of its emissions reduction by changing when the battery was charged to hours with lower MEFs and the schedule discharged the battery mainly during hours of high cost rather than high emissions.

The fact that the multi-objective schedules must charge the battery at specific hours in which the price and MEF are properly balanced will limit the maximum peak reduction that such schedules can provide. If enough houses in an area are charging batteries at the same time it will create a second peak which will eventually become so large that using the BESSs for peak load reduction is counterproductive. In a work by Mishra et al. [6] a proposed BESS with a scheduler was estimated to be capable of reducing peak power by $20 \%$ when installed in $22 \%$ of homes if the homes randomize when they begin charging their batteries. They found that if all batteries were charged at the same time then the maximum achievable peak reduction dropped to $8 \%$. 


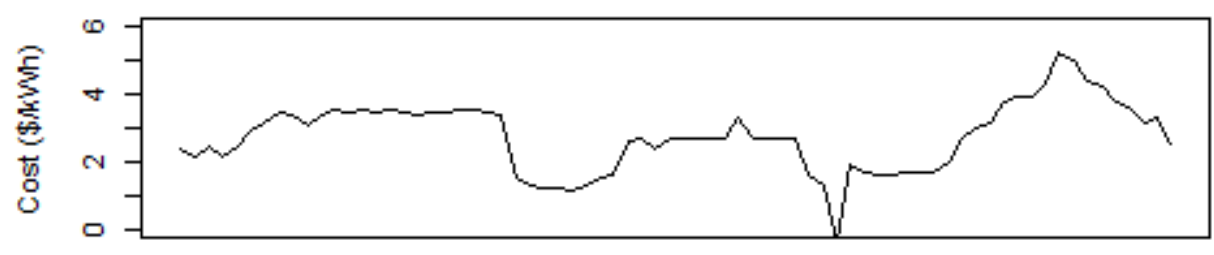

(a)

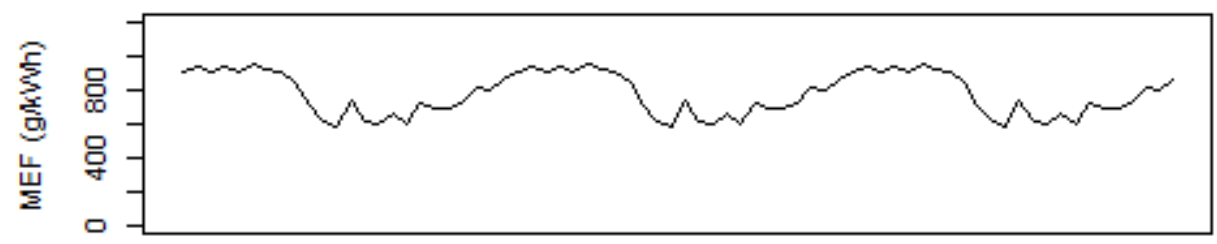

(b)

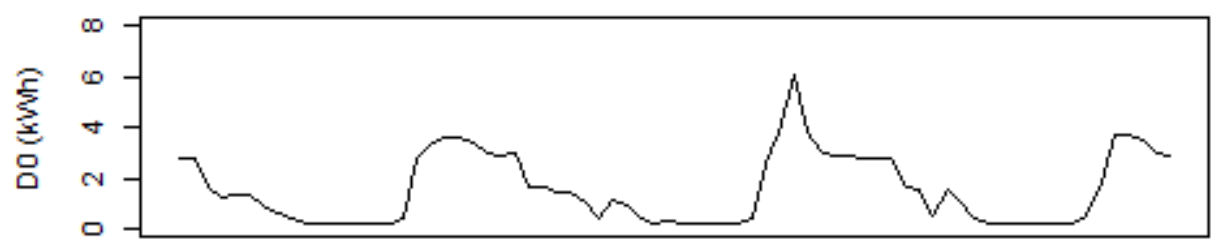

(c)

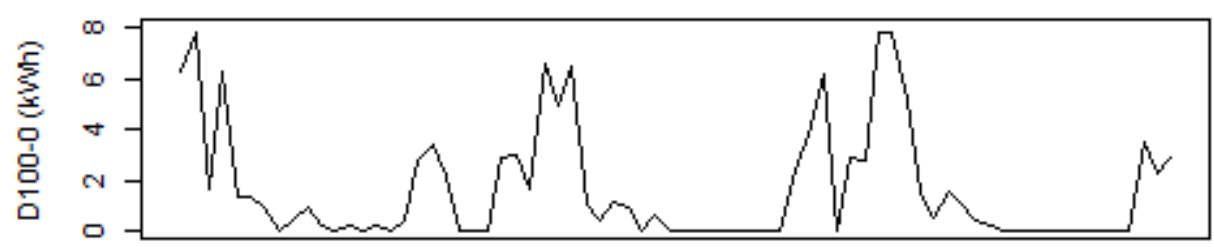

(d)

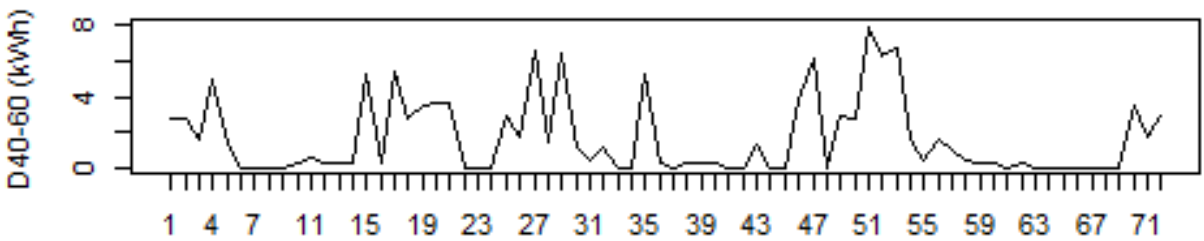

(e)

\section{Time (h)}

Figure 15: SPNO cost, MEF, and demand profiles from Wednesday through Friday.

Cost under DAP is in dollars (\$), MEF is in grams of $\mathrm{CO}_{2}$ per kilowatt hour (g/kWh), and Demands are in kilowatt hours (kWh). (a) Shows the price of electricity over time, (b) shows the MEF at each hour, (c) is the electricity demand of the household when no BESS is in use, (d) shows the electricity demand of the household when using the cost-only schedule, and (e) shows the electricity demand of the household when using the cut-off point schedule from the multi-objective optimization. The time starts Wednesday at the hour ending in 1 and goes until Friday at the hour ending in 24. 


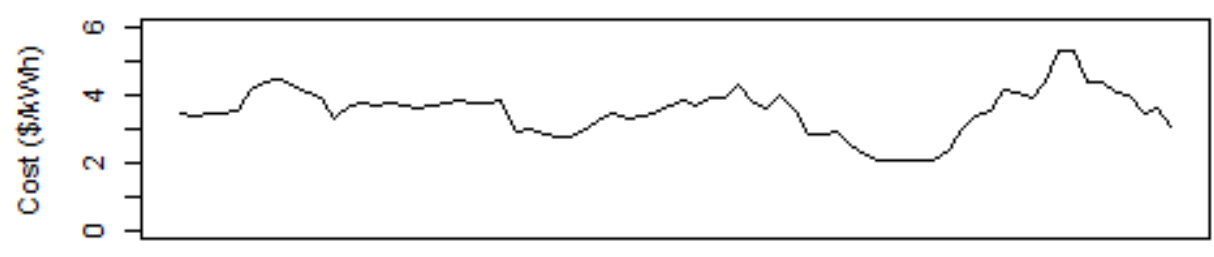

(a)

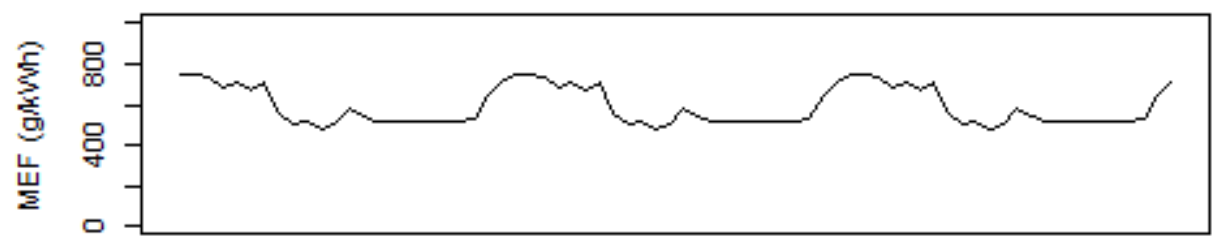

(b)

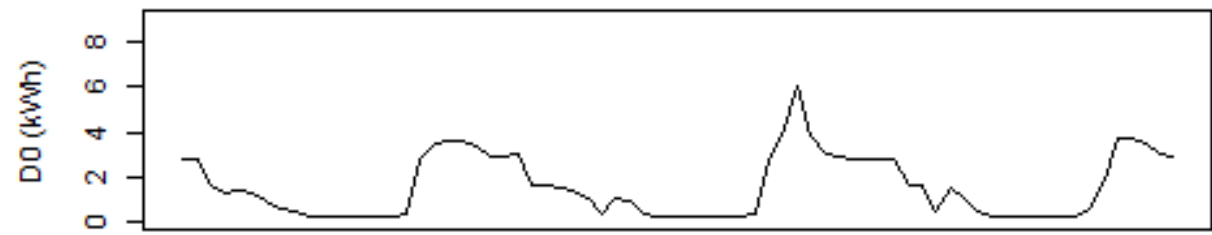

(c)

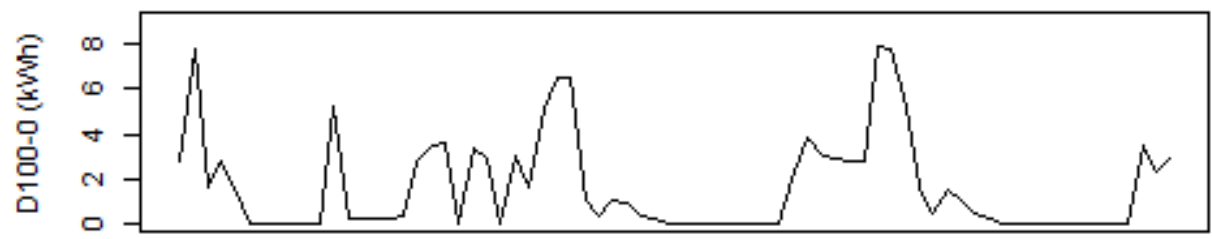

(d)

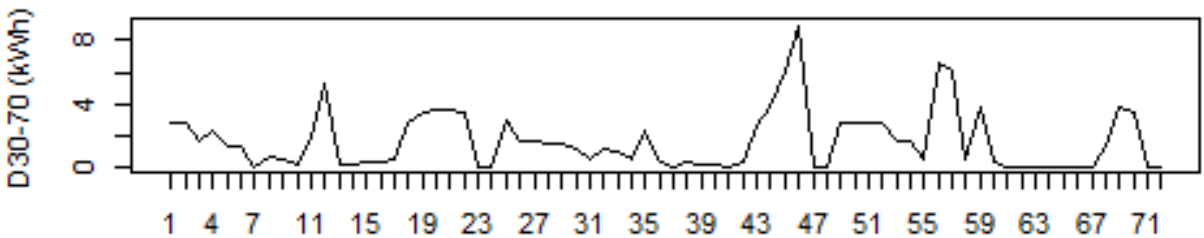

(e)

\section{Time (h)}

Figure 16: SRMV cost, MEF, and demand profiles from Wednesday through Friday.

Cost under DAP is in dollars (\$), MEF is in grams of $\mathrm{CO}_{2}$ per kilowatt hour (g/kWh), and Demands are in kilowatt hours (kWh). (a) Shows the price of electricity over time, (b) shows the MEF at each hour, (c) is the electricity demand of the household when no BESS is in use, (d) shows the electricity demand of the household when using the cost-only schedule, and (e) shows the electricity demand of the household when using the cut-off point schedule from the multi-objective optimization. The time starts Wednesday at the hour ending in 1 and goes until Friday at the hour ending in 24. 


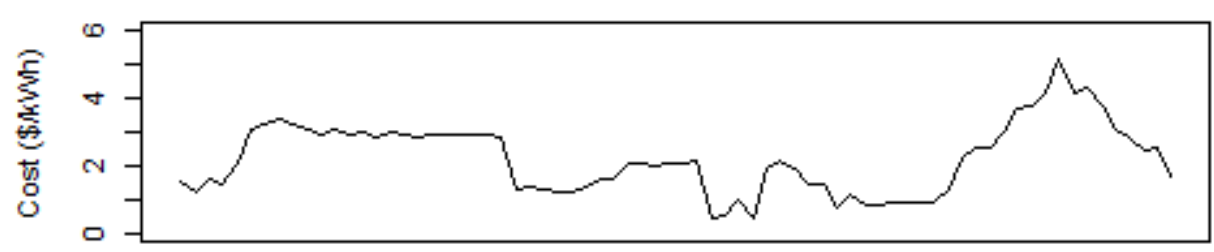

(a)

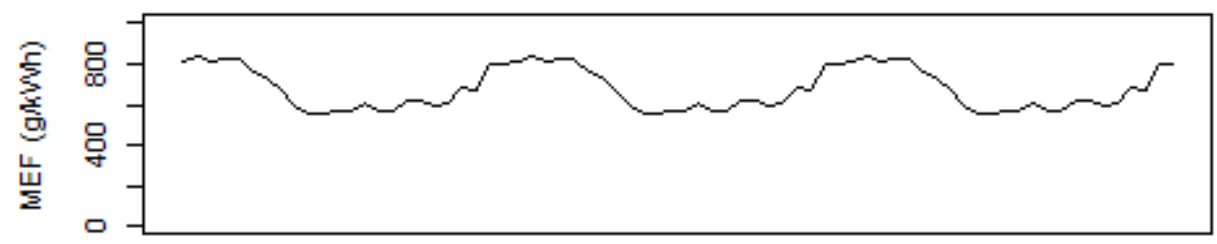

(b)

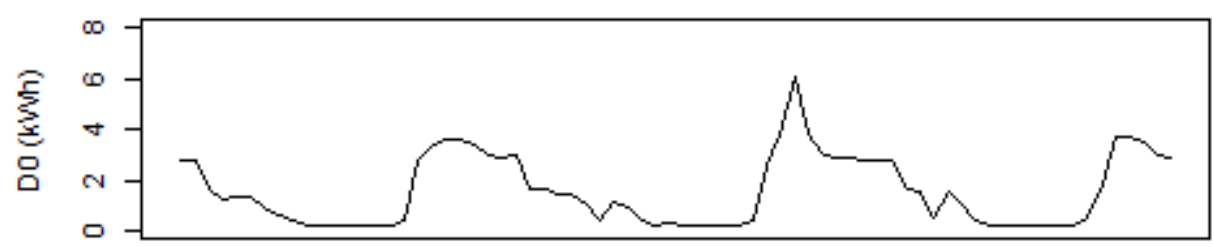

(c)

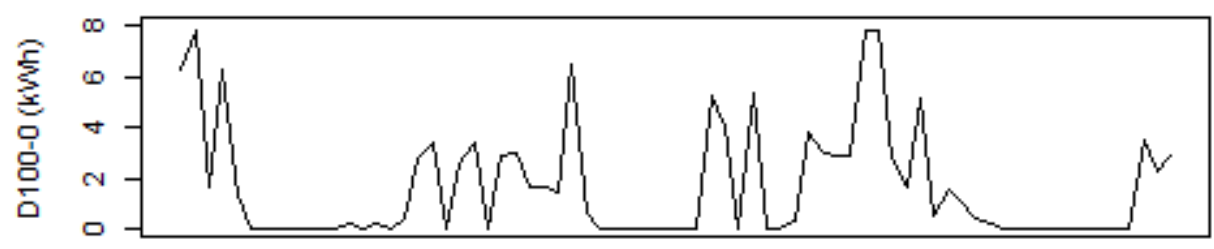

(d)

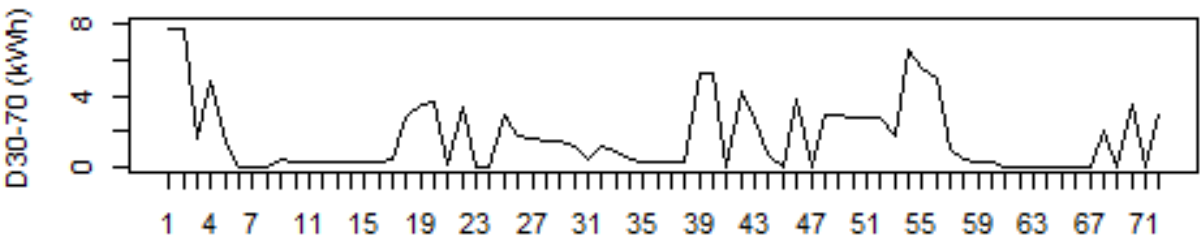

(e)

\section{Time (h)}

Figure 17: RMPA cost, MEF, and demand profiles from Wednesday through Friday.

Cost under DAP is in dollars (\$), MEF is in grams of $\mathrm{CO}_{2}$ per kilowatt hour (g/kWh), and Demands are in kilowatt hours (kWh). (a) Shows the price of electricity over time, (b) shows the MEF at each hour, (c) is the electricity demand of the household when no BESS is in use, (d) shows the electricity demand of the household when using the cost-only schedule, and (e) shows the electricity demand of the household when using the cut-off point schedule from the multi-objective optimization. The time starts Wednesday at the hour ending in 1 and goes until Friday at the hour ending in 24. 


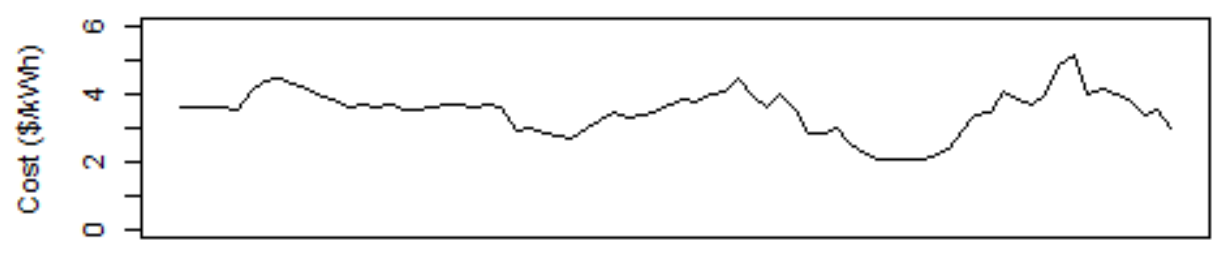

(a)



(b)

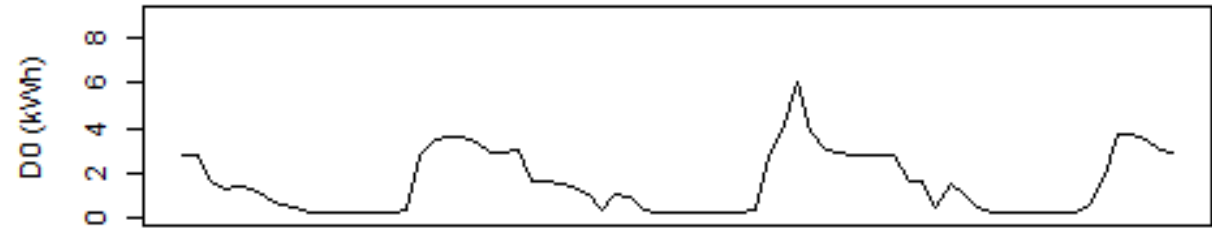

(c)

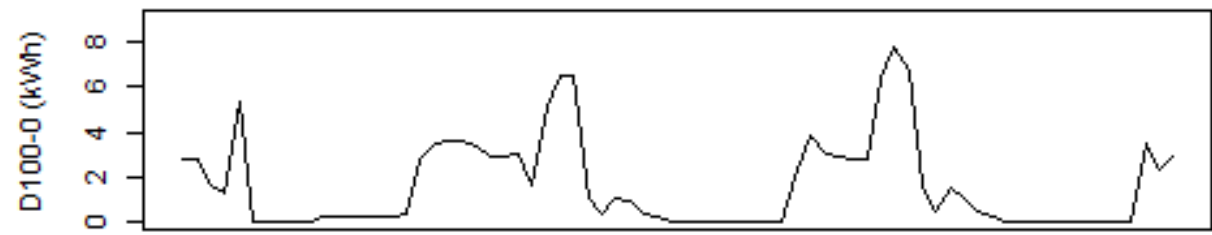

(d)

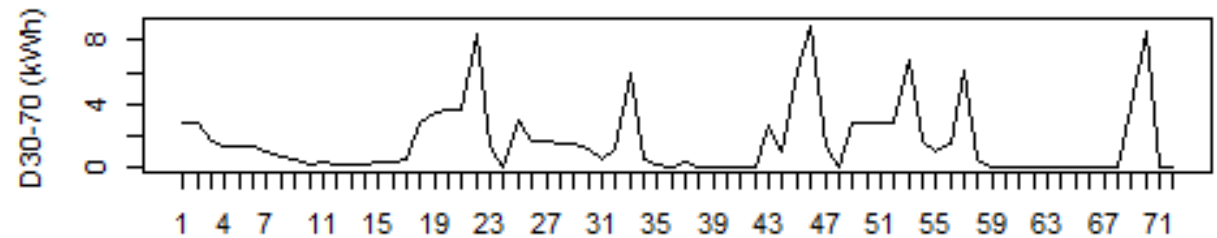

(e)

\section{Time (h)}

Figure 18: SPSO cost, MEF, and demand profiles from Wednesday through Friday.

Cost under DAP is in dollars (\$), MEF is in grams of $\mathrm{CO}_{2}$ per kilowatt hour (g/kWh), and Demands are in kilowatt hours (kWh). (a) Shows the price of electricity over time, (b) shows the MEF at each hour, (c) is the electricity demand of the household when no BESS is in use, (d) shows the electricity demand of the household when using the cost-only schedule, and (e) shows the electricity demand of the household when using the cut-off point schedule from the multi-objective optimization. The time starts Wednesday at the hour ending in 1 and goes until Friday at the hour ending in 24. 


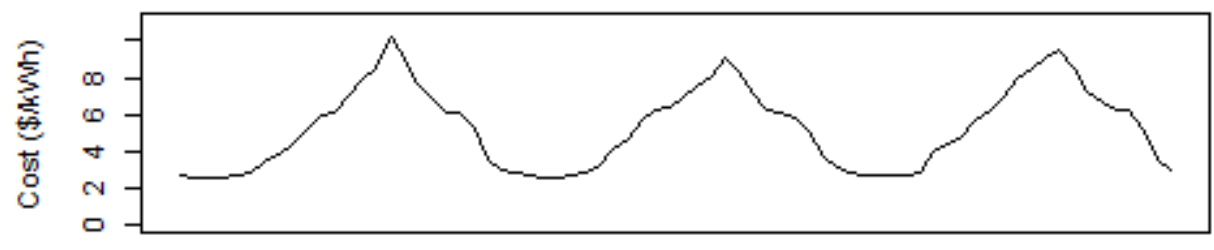

(a)

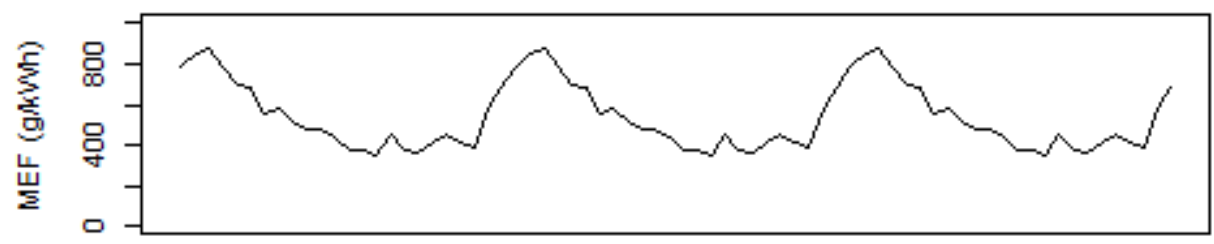

(b)

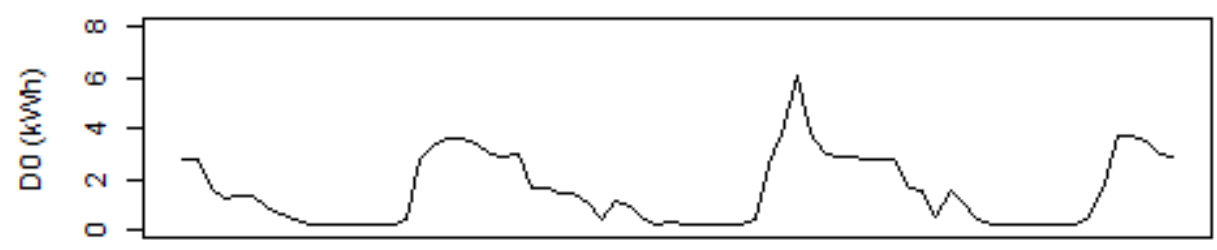

(c)

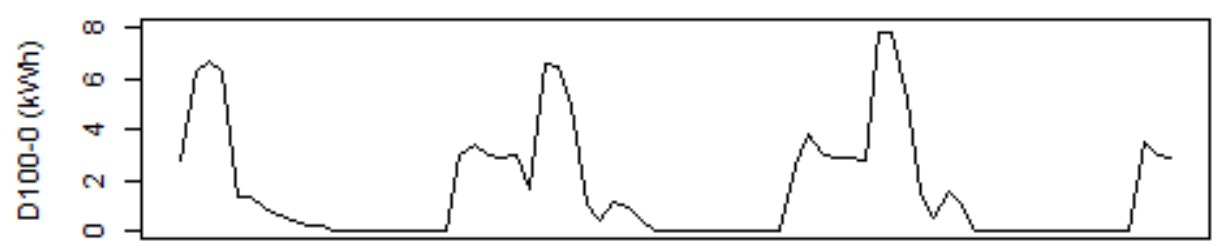

(d)

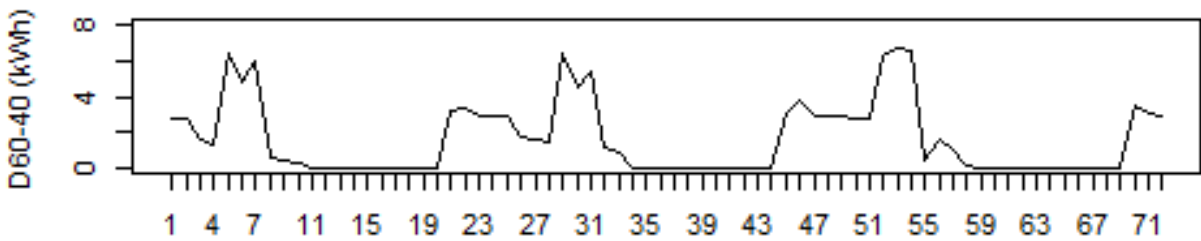

(e)

\section{Time (h)}

Figure 19: RFCM cost, MEF, and demand profiles from Wednesday through Friday.

Cost under DAP is in dollars (\$), MEF is in grams of $\mathrm{CO}_{2}$ per kilowatt hour (g/kWh), and Demands are in kilowatt hours (kWh).

(a) Shows the price of electricity over time, (b) shows the MEF at each hour, (c) is the electricity demand of the household when no BESS is in use, (d) shows the electricity demand of the household when using the cost-only schedule, and (e) shows the electricity demand of the household when using the cut-off point schedule from the multi-objective optimization. The time starts Wednesday at the hour ending in 1 and goes until Friday at the hour ending in 24.

\subsection{Perspective on $\mathrm{CO}_{2}$ Emission Levels}

To help gain perspective on the impact of not considering $\mathrm{CO}_{2}$ emissions in the scheduling of a BESS, Table 9 shows additional emission produced from using the cost-only model with the values extrapolated to an annual scale. The table also includes annual values for the emissions produced using the cut-off schedule from the multi-objective model for each reach region as well as values for the 
reduction in emissions from the multi-objective schedule compared to the cost-only schedule. The annual values in Table 9 are rough estimates calculated by multiplying the weekly values by 52 .

Table 10: Annual $\mathrm{CO}_{2}$ emissions from cost-only and multi-objective models.

\begin{tabular}{|c|c|c|c|}
\hline Region & $\begin{array}{l}\text { Cost Only } \\
\mathrm{CO}_{2}(\mathrm{~kg})\end{array}$ & $\begin{array}{c}\text { Cut-off } \\
\text { point } \\
\text { Schedule } \\
\mathrm{CO}_{2}(\mathrm{~kg})\end{array}$ & $\begin{array}{c}\mathrm{CO}_{2} \\
\text { reduced } \\
\text { from cost } \\
\text { only }(\mathrm{kg})\end{array}$ \\
\hline SPNO & 1450.69 & 152.77 & 1297.92 \\
\hline SRMV & 1022.24 & -181.04 & 1203.28 \\
\hline RMPA & 1165.17 & 121.01 & 1044.16 \\
\hline SPSO & 633.56 & -218.20 & 851.76 \\
\hline RFCM & 1998.39 & 1254.27 & 744.12 \\
\hline FRCC & 503.80 & -27.16 & 530.96 \\
\hline MROE & 646.87 & 202.27 & 444.60 \\
\hline NWPP & 656.39 & 235.19 & 421.20 \\
\hline SRVC & 326.19 & -28.76 & 354.95 \\
\hline MROW & 980.82 & 651.66 & 329.16 \\
\hline SRSO & 90.67 & -175.51 & 266.18 \\
\hline ERCT & 1006.25 & 865.33 & 140.92 \\
\hline CAMX & 314.78 & 196.80 & 117.98 \\
\hline RFCW & 713.33 & 615.79 & 97.54 \\
\hline AZNM & 344.11 & 259.66 & 84.45 \\
\hline SRMW & 1022.24 & 986.88 & 35.36 \\
\hline SRTV & 863.81 & 858.09 & 5.72 \\
\hline
\end{tabular}


The annual $\mathrm{CO}_{2}$ emissions from using the cost only model ranged from about 90 to $2000 \mathrm{~kg}$. The emissions from the multi-objective model ranged from a reduction of $218 \mathrm{~kg}$ to an increase of $1254 \mathrm{~kg}$. The emissions from the cost-only model were reduced by 5 to almost $1300 \mathrm{~kg}$ when using the cut-off point schedule from the multi-objective model.

For a different perspective on how much additional $\mathrm{CO}_{2}$ can potentially be emitted using the cost only model, emitting $2000 \mathrm{~kg}$ of $\mathrm{CO}_{2}$ is equivalent to burning and extra 225 gallons of gasoline a year or driving an extra 4,866 miles in the average passenger vehicle. More than half of the regions examined emit closer to $1000 \mathrm{~kg}$ of $\mathrm{CO}_{2}$ in a year which is equivalent to burning 113 gallons of gasoline or driving 2433 miles in the average passenger vehicle.

\section{Conclusions}

Initially 22 eGRID regions were analyzed to determine the difference between optimizing a BESS schedule to minimize cost and optimizing the schedule to minimize $\mathrm{CO}_{2}$ emissions in each region. In the majority of regions minimizing cost resulted in an increase in $\mathrm{CO}_{2}$ emissions and minimizing $\mathrm{CO}_{2}$ emissions caused the customer's electricity bill to rise.

Of the 22 regions, 12 were identified as having the best potential for benefiting from the multi-objective model based on both the scale of the emissions increase experienced when minimizing cost and the potential for trade-off between cost and emissions based on the difference between the cost-only and emissions-only optimization. These regions were SPNO, SRMV RMPA, SPSO, RFCM, FRCC, MORE, NWPP, MROW, ERCT, SRMW, and SRTV. The trade-off potential in each region was evaluated by determining how much $\mathrm{CO}_{2}$ emissions could be reduced at a price under $\$ 25 /$ ton of $\mathrm{CO}_{2}$. The regions with the best trade-offs based on this analysis were SPNO, SRMV, RMPA, SPSO, and RFCM. The regions FRCC, MORE, NWPP, MROW, SRVC, and SRSO can also benefit from the multi-objective schedule, but the impact is smaller. Reducing emissions in ERCT, SRMW, SRTV, CAMX, RFCW, and AZNM quickly exceeded the $\$ 25 /$ ton price. $\mathrm{CO}_{2}$ emissions could not be reduced in NEWE, NYUP, NYLI, and NYCW for less than $\$ 25 /$ ton. In most regions there is still an increase in emissions when using the multi-objective schedule, but the increase is significantly lower than that caused by the cost-only schedule.

In general the least expensive way to reduce emissions was changing the time at which the battery was charged to an hour later in the day. As the schedules begin to use the energy from the battery to displace demand from hours with high MEFs the potential savings the system can provide drop 
significantly. The schedules which provide the most significant emissions reduction provide fairly low cost reductions and most would not be economically practical for a BESS owner without some form of incentive. Utilities may consider incentivizing BESS owners to use a multi-objective schedule but they should take into account that such schedules will likely limit the potential peak load reduction that these systems can provide.

More work still needs to be done to fully understand the potential of multi-objective BESS schedules. The model should be tested with a variety of household demand profiles so that the effects of different demand profiles on the results can be analyzed. The model should also be used to model a full year of operation so that seasonal differences in MEFs can be accounted for. Also in practice the system will need to use some method of predicting demand which will have an impact on cost and emissions reduction which should be quantified. 


\section{References}

[1] Energy Information Administration, “Annual Energy Outlook 2015” pg. ES-7, 2015.

[2] A. Farqui, R. Hledik, S. Newell, and J. Pfeifenberger, "The Power of Five Percent How Dynamic Pricing Can Save \$ 35 Billion in Electricity Costs," pp. 1-10, 2007.

[3] State of the Markets Report 2008. Technical report, Federal Energy Regulatory Commission, August 2009.

[4] E. S. Hittinger and I. M. L. Azevedo, "Bulk Energy Storage Increases United States Electricity System Emissions," Environ. Sci. Technol., vol. 49, no. 5, pp. 3203-3210, Mar. 2015.

[5] Meyer, Robinson, "A Reader's Guide to the Paris Agreement" The Atlantic , 2015.

[6] A. Mishra, D. Irwin, P. Shenoy, J. Kurose, and T. Zhu, "SmartCharge: Cutting the Electricity Bill in Smart Homes with Energy Storage."

[7] C. W. Gellings, "The concept of demand-side management for electric utilities," Proc. IEEE, vol. 73, no. 10, pp. 1468-1470, 1985.

[8] M. L. Telson, "The Economics of Alternative Levels of Reliability for Electric Power Generation Systems," Bell Journal Econ., vol. 6, no. 2, pp. 679-694, 1975.

[9] M. Boiteux, "Peak-Load Pricing," J. Bus., vol. 33, no. 2, pp. 157-179, 1960.

[10] D. Aigner, "The Residential Electricity Time-of-Use Pricing Experiments: What Have We Learned?," Natl. Bur. Econ. Res., vol. Social Exp, pp. 11-54, 1985.

[11] CRA, "IMPACT EVALUATION OF THE CALIFORNIA STATEWIDE PRICING PILOT," Methodology, 2005.

[12] R. Deng, Z. Yang, M.-Y. Chow, and J. Chen, "A Survey on Demand Response in Smart Grids: Mathematical Models and Approaches," IEEE Trans. Ind. Informatics, vol. 11, no. 3, pp. 1-1, 2015.

[13] A. H. Mohsenian-Rad and A. Leon-Garcia, "Optimal residential load control with price prediction in real-time electricity pricing environments," IEEE Trans. Smart Grid, vol. 1, no. 2, pp. 120-133, 2010. 
[14] Z. Zhu, J. Tang, S. Lambotharan, W. H. Chin, and Z. Fan, "An integer linear programming based optimization for home demand-side management in smart grid," Innov. Smart Grid Technol. (ISGT), 2012 IEEE PES, pp. 1-5, 2012.

[15] Z. Chen, L. Wu, and Y. Fu, "Real-Time Price-Based Demand Response Management for Residential Appliances via Stochastic Optimization and Robust Optimization," IEEE Trans. Smart Grid, vol. 3, no. 4, pp. 1822-1831, Dec. 2012.

[16] F. De Angelis, M. Boaro, D. Fuselli, S. Squartini, F. Piazza, and Q. Wei, "Optimal home energy management under dynamic electrical and thermal constraints," IEEE Trans. Ind. Informatics, vol. 9, no. 3, pp. 1518-1527, 2013.

[17] H. J. Vermeulen and T. Nieuwoudt, "Optimisation of residential electric appliance load schedules to minimise expenses to the client," in 2014 49th International Universities Power Engineering Conference (UPEC), 2014, pp. 1-6.

[18] D. Mirabbasi and S. Beydaghi, "Optimal scheduling of smart home appliances considering PHEV and energy storage system," in 2015 4th International Conference on Electric Power and Energy Conversion Systems (EPECS), 2015, pp. 1-6.

[19] S. Squartini, D. Fuselli, M. Boaro, F. De Angelis, and F. Piazza, "Home energy resource scheduling algorithms and their dependency on the battery model," 2013 IEEE Comput. Intell. Appl. Smart Grid, pp. 122-129, Apr. 2013.

[20] M. Gitizadeh and H. Fakharzadegan, "Effects of electricity tariffs on optimal battery energy storage sizing in residential PV/storage systems," in 2013 International Conference on Energy Efficient Technologies for Sustainability, ICEETS 2013, 2013, pp. 1072-1077.

[21] D. Zhu, S. Yue, Y. Wang, Y. Kim, N. Chang, and M. Pedram, "Designing a residential hybrid electrical energy storage system based on the energy buffering strategy," in 2013 International Conference on Hardware/Software Codesign and System Synthesis, CODES+ISSS 2013, 2013, pp. 1-9.

[22] H. Karami, M. J. Sanjari, S. H. Hosseinian, and G. B. Gharehpetian, "An optimal dispatch algorithm for managing residential distributed energy resources," IEEE Trans. Smart Grid, vol. 5, no. 5, pp. 2360-2367, 2014. 
[23] C. Guan, Y. Wang, X. Lin, S. Nazarian, and M. Pedram, "Reinforcement learning-based control of residential energy storage systems for electric bill minimization," in 2015 12th Annual IEEE Consumer Communications and Networking Conference, CCNC 2015, 2015, pp. 637-642.

[24] R. K. Lam, D. H. Tran, and H.-G. Yeh, "Economics of residential energy arbitrage in california using a PV system with directly connected energy storage," in 2015 IEEE Green Energy and Systems Conference (IGESC), 2015, pp. 67-79.

[25] P. Zhuang and H. Liang, "Energy Storage Management in Smart Homes Based on Resident Activity of Daily Life Recognition," in 2015 IEEE International Conference on Smart Grid Communicaitons (SmartGridComm) : Architectures, Control and Operation for Smart Grids and Microgrids, 2015, pp. 641646.

[26] A. Saez-de-Ibarra, E. Martinez-Laserna, C. Koch-Ciobotaru, P. Rodriguez, D.-I. Stroe, and M. Swierczynski, "Second life battery energy storage system for residential demand response service," in 2015 IEEE International Conference on Industrial Technology (ICIT), 2015, pp. 2941-2948.

[27] P. Denholm and G. L. Kulcinski, "Life cycle energy requirements and greenhouse gas emissions from large scale energy storage systems," Energy Conversion and management, vol.45, pp. 2153-2172, 2004.

[28] S. P. Holland and E. T. Mansur, "Is Real-Time Pricing Green?: the Environmental Impacts of Electricity Demand Variance," Rev. Econ. Stat., vol. 90, no. 3, pp. 550-561, 2008.

[29] A. Hadland, "Marginal Emissions Factors for the United Kingdom Electricity System," Environ. Sci. Technol., vol. 46, pp. 4742-4748, 2009.

[30] I. Das and J. Dennis, "Normal-Boundary Intersection: An alternate method for generating pareto optimal points in multicriteria optimization problems," Soc. Ind. Appl. Math. J. Optim., no. 8, pp. 631657, 1998.

[31] I. Y. Kim and O. L. De Weck, “Adaptive weighted-sum method for bi-objective optimization: Pareto front generation," Struct. Multidiscip. Optim., vol. 29, no. 2, pp. 149-158, 2005.

[32] Umass.edu, 'Smart* Data Set for Sustainability', 2017. [Online]. Available: http://traces.cs.umass.edu/index.php/Smart/Smart [Accessed 8- Mar- 2017] 
[33] Sce.com, 'Time-of-Use (TOU) Rate Plans for Your Home', 2017. [Online]. Available: https://www.sce.com [Accessed 8- Mar- 2017]

[34] Ferc.gov, 'Regional Transmission Organization (RTO)/Independent System Operators (ISO)' 2017. [Online]. Available: https://www.ferc.gov/industries/electric/indus-act/rto.asp [Accessed 11- Mar- 2017]

[35] Epa.gov, 'eGRID subregion representational map', 2017. [Online]. Available: https://www.epa.gov/energy/egrid-subregion-representational-map [Accessed 8-Mar-2017]

[36] P. Luckow, E. A. Stanton, S. Fields, B. Biewald, S. Jackson, J. Fisher, and R. Wilson, "2015 Carbon Dioxide Price Forecast," Cambridge, Massachusetts, 2015.

[37] Epa.gov, 'Emissions \& Generation Resource Integrated Database', 2018. [Online]. Available: https://www.epa.gov/energy/emissions-generation-resource-integrated-database-egrid [Accessed 15Jan-2018] 